\title{
The Diels-Alder Reaction: an Update
}

\section{Timothy John Brocksom, Joanita Nakamura, Maria Lúcia Ferreira and Ursula Brocksom}

\author{
Departamento de Química, Universidade Federal de São Carlos, CP 676, 13565-905, São Carlos - SP, Brazil
}

\begin{abstract}
Na última década tem havido um enorme progresso na reação de Diels-Alder, principalmente nas aplicações sintéticas da versão intramolecular (IMDA) e sua variação macrocíclica transanular (TADA). Esta revisão pretende abordar estas inovações, enfocando a relação fundamental entre os conceitos sintéticos e os avanços experimentais, e com o envolvimento crescente dos estudos teóricos relacionados.
\end{abstract}

The last ten years have seen an explosive growth in synthetic applications of the Diels-Alder reaction, principally the intramolecular (IMDA) reaction but also the transannular (TADA) version. In this review we present these developments with special emphasis on the synthetic concepts and the experimental results and include related theoretical studies.

Keywords: Diels-Alder reaction, intramolecular, transannular

\section{Introduction}

In this update on the Diels-Alder reaction we would like to present an overview on how this very important reaction has progressed in the last decade, since the last spate of monographs and reviews appeared in the literature ${ }^{1-3}$, and which deal with the reaction in the overall sense.

Initially we present the Diels-Alder reaction in a generalised form, much as discovered over seventy years ago $^{1-3}$, so that its present relevance as probably the single most important reaction in the synthetic organic chemist's tool-box is clear.

Thus, the original version of the Diels-Alder reaction (Scheme 1) joins together a wide variety of conjugated dienes and alkenes with electron withdrawing groups (the dienophiles), to produce a cyclohexene ring in which practically all six carbon atoms can be substituted as desired.
The reaction may be executed under relatively simple reaction conditions by heating together the two components, diene and dienophile, in non-polar solvents, followed by evaporation which leads usually to high yields of the product(s). The reaction is disciplined by the WoodwardHoffmann rules ${ }^{4-6}$ as a $\left[4_{\pi} 4_{s}{ }_{\pi}\right.$ s $]$ cycloaddition occurring in a concerted but probably not symmetrically synchronous fashion, thus leading to highly predictable product structures in which two new carbon-carbon sigma bonds are formed in a stereospecific manner with the creation of up to four new stereogenic centres. The classical empirical rules have now found strong theoretical basis in the WoodwardHoffmann rules, with regards to regiochemistry ("ortho" and "para" orientations) and stereochemistry (endo transition state kinetically favoured over the exo transition state in most of the reactions $)^{1-6}$. The practising synthetic organic chemist will certainly be well aware of the kinds of dienes and<smiles>[2H]C([B])=C(C)C(C)=C(F)F</smiles><smiles>[X]C(I)=C([M])C(C)(C)C</smiles>

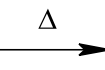

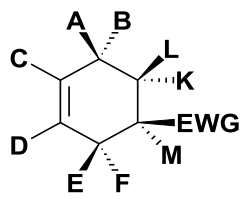

$A-F$ and $\mathrm{K}-\mathrm{M}$ : substituents; EWG: electron withdrawing group

Scheme 1.

Dedicated with admiration and respect to Professor Nicola Petragnani, for his many relevant contributions to the organic chemistry of selenium and tellurium

* email: brocksom@zaz.com.br 
dienophiles that may be combined successfully, and by way of simple frontier orbital theory ${ }^{4,5}$ be perfectly capable of predicting the major (or unique) product to be expected from the reaction. The reverse process of retrosynthetic analysis ${ }^{7}$ is also well established for transforming cyclohexene/ cyclohexane containing structures into appropriate dienedienophile combinations.

Having thus established a background point, this update plans to take the reader into the newer possibilities that have become fact in the last decade. It is not our intention to review earlier developments involving Lewis acid catalysis, very high pressures or other special techniques ${ }^{1-3,8}$, or the inverse electron demand version ${ }^{1-4}$. Newer aspects of cycloadditions ${ }^{9}$ and carbocycle constructions ${ }^{10,11}$ have been reviewed, including developments in Diels-Alder chemistry, as well as the related [4+3] IMDA reaction of dienes with allylic carbocations ${ }^{12}$. The use of sequential Diels-Alder reactions has also been highlighted recently ${ }^{13}$.

The Diels-Alder reaction has now become an important research area for theoretical chemists, with regard to the finer details of the transition state and the energetics of the process, and with special concern for entropy and activation energies $^{14-16}$.

On a completely different front it is now well accepted that the Diels-Alder reaction can be an important biosynthetic process ${ }^{15,17-23}$, and several publications include discussions on the existence of the enzyme DielsAlderase $\mathrm{e}^{15,19-23}$. The presentation which follows shows that the correct combination of diene and dienophile, using some kind of chemical linkage to hold the partners in the correct orientation and at the correct distance, can lead to very low activation energies and therefore to situations in nature in which a true enzyme may be superfluous ${ }^{24}$.

A final introductory point illustrates a powerful synthetic strategy of Diels-Alder chemistry as a protecting group and temporary scaffold (or template), for the manipulation of the sensitive multiple functionalities of diene or dienophile types. In this approach the sensitive diene or dienophile portions of the molecules are tied up with a convenient partner in a Diels-Alder reaction, the cycloadduct is then chemically modified in accordance with the synthetic plan and finally undergoes a retro Diels-Alder reaction to liberate the desired product ${ }^{25}$. For example, the cycloaddition product of a reactive $\alpha, \beta$-enone function with cyclopentadiene, can be submitted to the required chemo-, regio- and stereoselective reactions, dominated in part by the expected endo-cycloadduct structure, before retro DielsAlder reaction unravels a much more complex product. Clearly the same synthetic sequence could not have been executed on the enone itself, with the desired efficiency and selectivity, as demonstrated for the transformation of para-benzoquinone into the monoterpene (-)-iridolactone (Scheme 2; equation 1$)^{26}$. In a similar vein the cyclopentadiene dimer itself (Scheme 2; equation 2) can be suitably modified and then a retro Diels-Alder reaction furnishes a useful chiral cyclopentenone derivative, as a diene precursor for a further Diels-Alder cycloaddition ${ }^{27}$. In both of these examples intermediates undergo kinetic enzymatic resolutions with lipases, thus producing enantiopure cyclopentene derivatives.
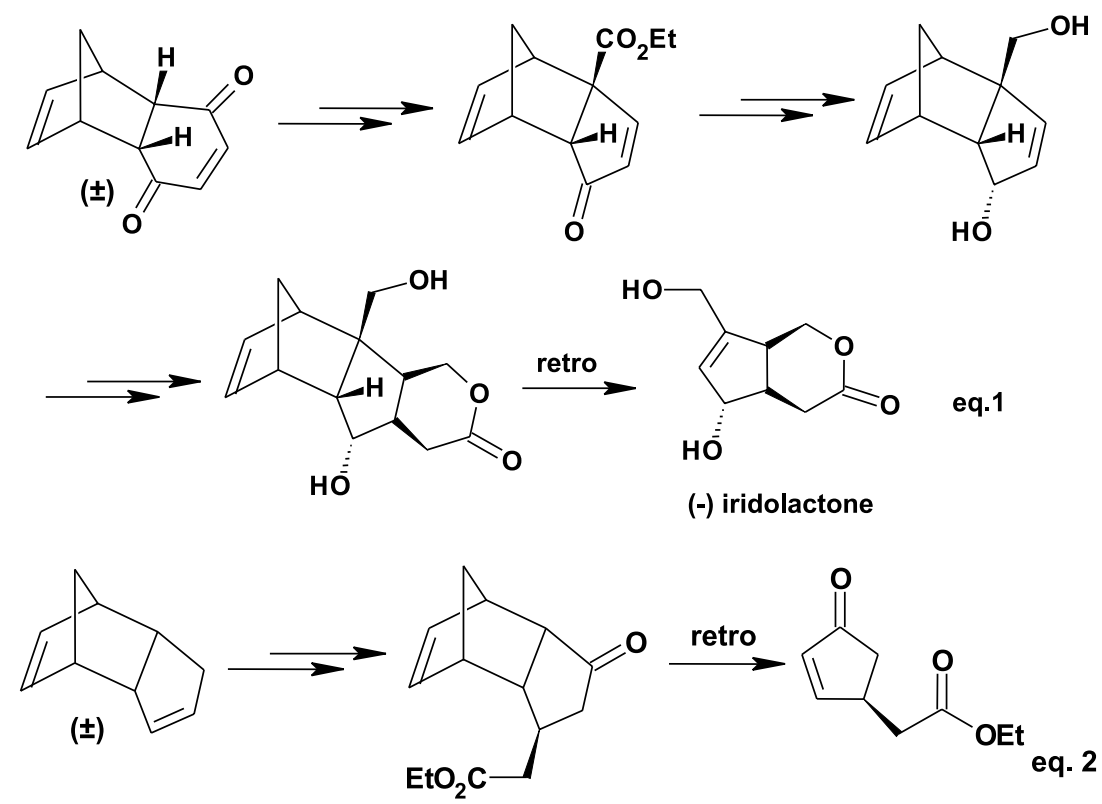

Scheme 2. 


\section{The IMDA Variation}

With the basic and relevant empirical facts well established, and the Woodward-Hoffmann rules allowing predictability of the expected structures to be produced in the classical intermolecular reaction, it became of interest to study ways to alter or circumvent the observed chemo-, regio- and stereoselectivities, and induce enantioselectivity ${ }^{28}$. These aspects will be considered within the discussion of the intramolecular Diels-Alder (IMDA) reaction ${ }^{29-36}$. In the period under review (1990 to the present) over 650 publications have appeared which deal directly with the IMDA reaction in synthesis, and this has determined a very selective presentation.

The first reports on the IMDA reaction appeared in the fifties and sixties and were based upon the desire to produce polycyclic structures incorporating this cycloaddition as the key step (Scheme 3). The triene precursor strongly suggests a carbonyl group conjugated to the alkene dienophile partner. As the initial and principal objective was the synthesis of bicyclic products containing the expected cyclohexene ring fused to a five, six, or seven membered ring, the accumulated knowledge of the IMDA reaction provided detailed information about the diene portion, the dienophile portion and the kind of carbon chain (with or without heteroatoms) necessary for a successful reaction $^{29-33}$.

It had also been established that IMDA reactions should be conducted under thermolytic conditions, as very high pressures were prematurely considered irrelevant, and Lewis acid catalysis seemed to have little effect as far as selectivity was concerned. These aspects have been very well detailed in several excellent reviews ${ }^{29-33}$.

\section{Competing Reactions}

The question of the IMDA reaction acting in competition with the bimolecular intermolecular reaction does not seem to have been specifically investigated, which suggests that the IMDA is kinetically much more favoured and therefore the intermolecular reaction products are not observed in significant amounts (Scheme 3). We have however noted that many IMDA reactions are run at relatively low concentrations (generally around $10^{-3} \mathrm{~mol} \cdot \mathrm{L}^{-1}$ ) perhaps with an intuitive respect for the possibility of competing intermolecular reactions. Also, [4+2] cycloadditions can co-exist with [1,5] sigmatropic hydrogen shifts and Alder-ene rearrangements (Scheme 3; see below for further discussion), under normal thermolytic conditions, and these other two pericyclic reactions are quite relevant in the intramolecular situation, and specially so in the TADA variation.

\section{Electronic Effects}

The Diels-Alder reaction is a pericyclic reaction under complete stereoelectronic control, but is strongly influenced by electronic and steric effects in both diene and dienophile. However, the importance of these two effects is quite different in the intermolecular version and in the IMDA and TADA reactions.

As to the basic electronic loading on the dienophile partner, which requires conjugated electron withdrawing groups for activation, this is not necessarily the case in the IMDA and TADA reactions. Simple substituted ethylenes and ethynes do not give Diels-Alder products in good yields in the intermolecular version even at very high pressures, whereas convenient linkage to the diene partner allows cycloaddition. For example (Scheme 4; equation 1), the Abad group in Spain has made very interesting use of the unactivated isopropenyl group present in suitably substituted and chiral carvone derivatives, in the synthesis of polycyclic higher terpenoids ${ }^{37}$. In a second example (Scheme 4; equation 2), Padwa and co-workers have reacted an unactivated terminal double bond linked to an $\alpha$-furan position and successfully cyclised this doubly unreactive molecule ${ }^{38}$.

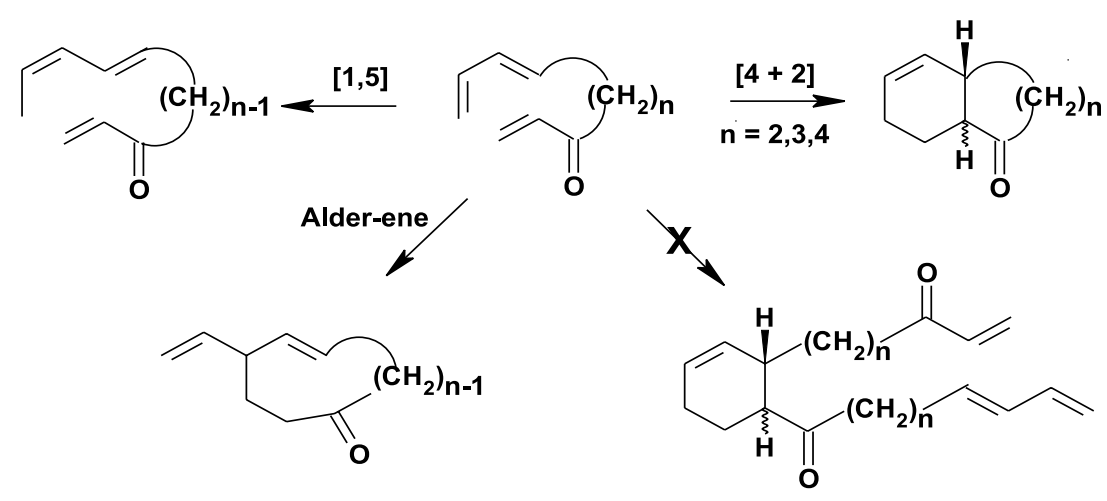

Scheme 3. 
<smiles>C=C/C(C)=C\CCC1(C(C)=O)CC(C)=CC[C@H]1C(=C)C</smiles><smiles>C=CCN(C)C(=O)Cc1ccco1</smiles>

Scheme 4.

The same is true for dienes with electron withdrawing groups, disfavouring the intermolecular reaction with another dienophile, but acting as diene and as dienophile in a bimolecular reaction. On the other hand, the IMDA reaction can be quite successful as seen in the following example (Scheme 5). The synthesis of himandravine involves the IMDA reaction of a diene tethered through an ester group to a relatively unactivated dienophile which is also a diene ${ }^{39}$, thus demonstrating chemoselectivity as well.

\section{Steric Effects}

Steric effects can also be pronounced in the intermolecular version, specially at the terminal carbon atom of the diene. The $E$-substituted dienes react normally whereas their $Z$ isomers are notoriously sluggish, requiring special conditions of high pressure or catalysis ${ }^{40-41}$. The definitive case is the terminally gem-disubstituted diene which usually defies all attempts at [4+2] cycloaddition, usually preferring the [1,5] hydrogen shift and posterior Diels-Alder reaction of the new diene $^{42}$. However, many studies in taxol chemistry have given ample evidence of the IMDA reaction overcoming this steric problem, and the Fallis group has thoroughly investigated the possibilities in this field ${ }^{34-36}$. Scheme 6 shows two examples which demonstrate approaches to taxol synthesis involving the IMDA reaction as the key step, and where Lewis acids ${ }^{43}$ (equation 1 ) and very high pressure ${ }^{44}$ (equation 2 ) were essential for effective reactions.

\section{Chemoselectivity}

The electronic and steric effects which define diene and dienophile reactivity in the intermolecular situation are well known $^{1-3}$, so that molecules containing more than one diene function can be reacted chemoselectively with molecules
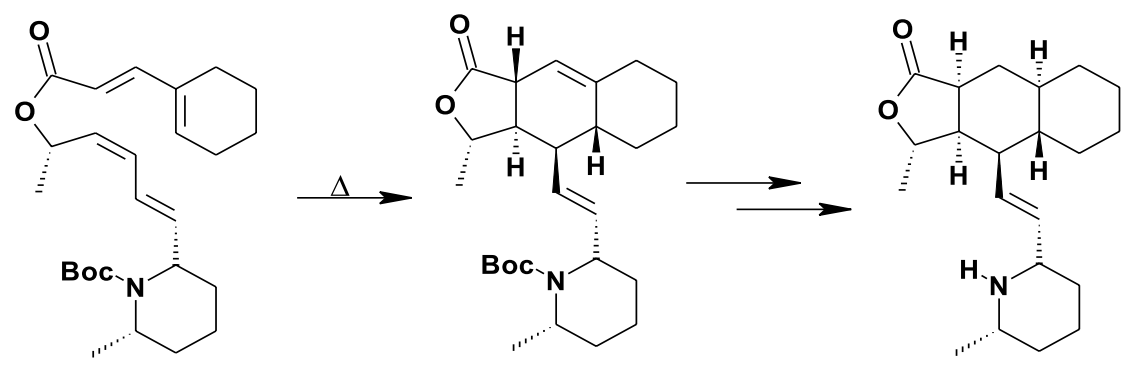

himandravine

Scheme 5. 
<smiles>C=CC(=O)[C@H]1CCCC[C@]1(C)CCC(C(=C)C)=C(C)C</smiles><smiles>C=CC(=O)C[C@@H](CC(C(=C)C)=C(C)C)OC(C)(C)C</smiles>

19 kbar<smiles>CC1=C2CCCC(=O)CCCC2CC1</smiles>

OTBS
Scheme 6.

containing more than one dienophile moiety, and many interesting experiments have been devised and conducted with this objective in mind. The dienes can be present as a conjugated triene or as separate dienes, while the dienophiles can also be in extended conjugation or in two different sites in the molecule. For instance, the Wenkert-Fringuelli-Taticchi groups have performed extensive investigations on the extended and double dienophile situations ${ }^{45}$, as can be seen in the example in Scheme 7. The general case for diene chemoselectivity has been reviewed ${ }^{2}$.

However, in the IMDA variation the coupling of the diene and dienophile partners through a chain of atoms defines now by physical constraints which possible cycloadduct will be produced. The example in Scheme 5 illustrates this point, and the Boeckman group has also unequivocally demonstrated this in the IMDA reaction of a molecule containing a conjugated triene unit and an extended dienophile (Scheme 8$)^{46}$.

In the following schemes protecting groups are represented as a generic $\mathrm{P}$, and the carboalkoxy group as $\mathrm{E}$ in order to simplify the structures shown.

\section{Regioselectivity}

In a very similar sense, the diene-dienophile chain combinations determine the regiochemistry of cycloaddition between the two possible orientations. These relationships have been formalised as modes ${ }^{30}$ or types $^{31}$ and are shown in Scheme 9. Modes I through IV are denominated type I (or 1) where the chain is linked from the terminal carbon atom of the diene, whereas modes $\mathrm{V}$ and VI are named type II (or 2) as the chain is linked from the non-terminal carbon atom of the diene.

Mode I is generally much preferred over mode II, as is mode V over mode VI, for obvious strain reasons, although lengthening the chain between the diene and the dienophile will finally allow modes II and VI to participate. In the case of the Z-dienes as in modes III and IV, there is clear evidence of preference for mode III, while once again a longer chain may favor mode IV. This leads to the important conclusion that the dominant regiochemistry, as defined by the coefficients of atomic orbitals ${ }^{5,6}$ in intermolecular reactions, can be overruled by linking the partners in the opposite orientation as long as the chain is not too long.<smiles>CC12C=CC(=O)C=C1CCCC2</smiles><smiles>[R]C=C([R])C=C</smiles>

a, $\mathbf{R}=\mathbf{R}^{\prime}=\mathbf{H}$

b, $R=M e, R^{\prime}=H$

c, $R=H, R^{\prime}=M e$
$\stackrel{\mathrm{AlCl}_{3}}{\longrightarrow}$<smiles>[R]C1=CCC2(C)[C@@H](C(=O)C=C3CCCCC32C)[C@H]1[R]</smiles>

(+ 8 - epi)

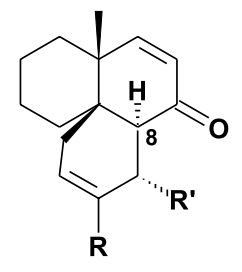

(+ 8 - epi)

Scheme 7.<smiles>CC(/C=C/C=C/C([OH2+])CC(C)/C=C(\C)C1=CC(=O)OC(C)(C)O1)=C\CC(C)C(C)(C)O</smiles> 


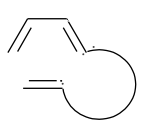

I

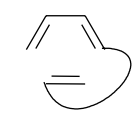

II

(E)- dienes

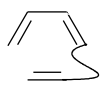

III

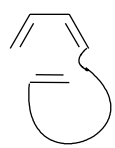

IV

(Z)- dienes

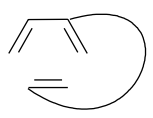

VI
Scheme 9.

\section{Stereoselectivity}

The stereochemistries of diene to chain and dienophile to chain are extremely relevant for defining the stereo- chemistry of the cycloadduct, with special reference to the ring junctions. The stereoselective transfer of alkene stereochemistry ( $\mathrm{sp}^{2}$ carbon) to create new $\mathrm{sp}^{3}$ stereogenic centres is a very well established and fundamental concept in synthesis, as is the opposite process, and well demonstrated in the case of the Diels-Alder reaction.

The kinetically preferred intermolecular endo transition state can be overruled by conformational requirements which demand an exo transition state. Thus different stereoselectivities can be pre-ordained by the judicious choice of the diene, the dienophile and principally how the chain links them together. This point has been very well treated in reviews ${ }^{29-33}$ with special attention being given by $\mathrm{Craig}^{32}$, and is currently of experimental and theoretical interest to the Houk group ${ }^{16}$ (Scheme 10).

Many other experimental and theoretical studies have investigated the question of stereoselectivity in the last decade, and some further examples are shown in Scheme 11. The Houk and Clark Still groups have investigated the IMDA reactions of 1,3,8-nonatriene, 1,3,9-decatriene and $1,3,10$-undecatriene with regard to stereoselectivities, activation parameters and modelling of the transition state ${ }^{47}$ (Scheme 11; equation 1). The related esters (Scheme 11; equation 2) have been studied ${ }^{48,49}$ both experimentally and theoretically with regard to endo and exo transition states<smiles>C=C/C(C)=C/C[C@H](C)OC(=O)/C=C/C(C)C</smiles>

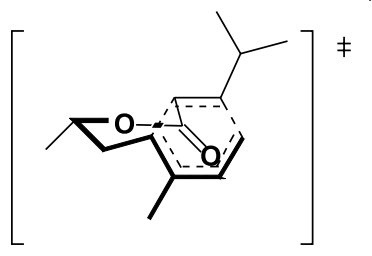<smiles>CC(C)C</smiles>

F

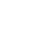
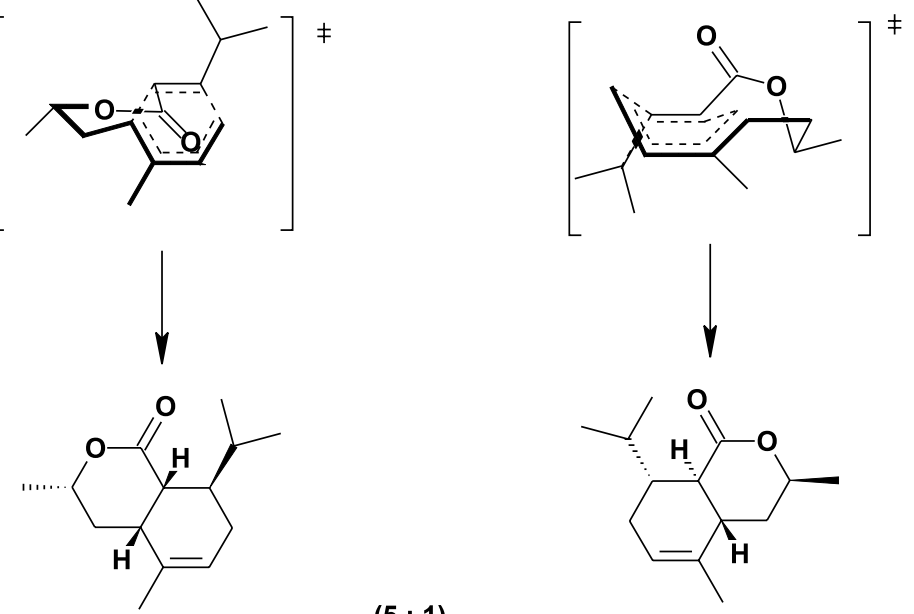

(5: 1) 
and their asynchronous nature, in which the internal carboncarbon bond is more developed than the peripheral carboncarbon bond. The influence of diene geometry has been determined experimentally ${ }^{50}$ for the case of trienes separated by a simple trimethylene chain (Scheme 11; equation 3), with Lewis acid catalysis being able to alter substantially the stereoselectivity from that observed under thermal conditions. The fascination with the diterpene eleutherobin has led to detailed studies on the stereoselective IMDA reaction of 1,3,9-decatrienoates (Scheme 11 ; equation 4 ), in which a remote stereocontrol group has a decisive impact upon preferred ester conformations, boatchair conformations and endo-exo conformations at the transition state ${ }^{51,52}$, as already mentioned above and illustrated in Scheme 10.
Chains, Bridges, Tethers, Spacers, and Linkers

The developments in this area have opened up new possibilities for application of the IMDA reaction which are now becoming more and more commonplace. This involves the very basic question of the nature of the chain (or bridge), which at first sight was, and still is, to be an intrinsic part of the product structure and therefore a highly important component of the cycloaddition precursor. However, it was soon realised that the functionalities present and the length of the chain were also important for the success of the IMDA reaction. This is now so true that the chain may be incorporated into the final product as is, or by functional group modification, or simply discarded after having served its purpose

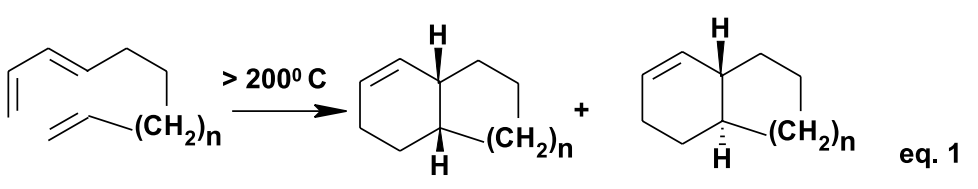

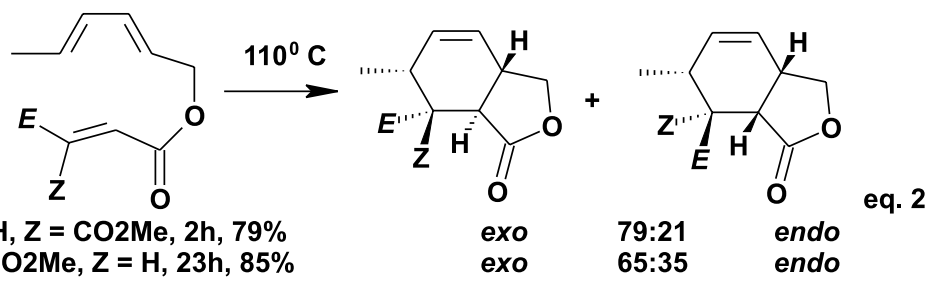

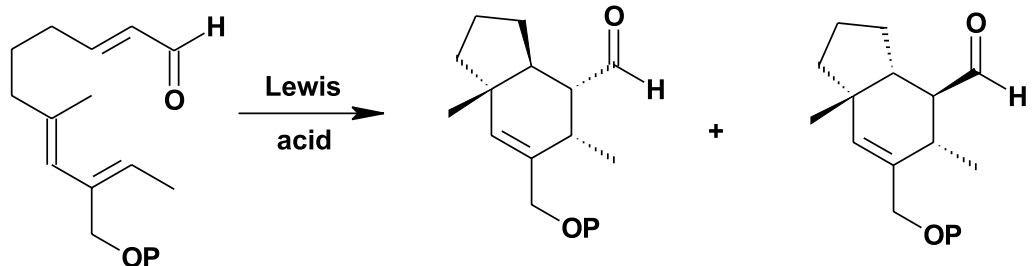<smiles>C/C=C(\C=C(\C)CCC/C=C/C=O)CO</smiles>

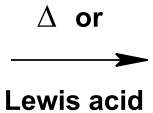

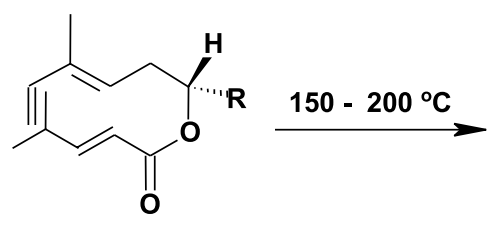

$\mathrm{R}=\mathrm{Me}$ or $\mathrm{t}-\mathrm{Bu}$<smiles>C[C@H]1C(C[OH2+])=C[C@]2(C)CCC[C@@H]2[C@H]1C=O</smiles>

eq. 3

eq. 4 


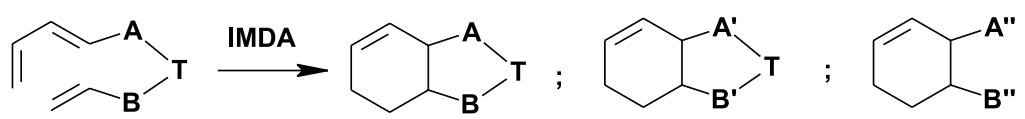

Scheme 12.

(Scheme 12; A and B are the original substituents linked by a tether T, while A', B', A" and B" are transformed functionalities).

This last analysis brings in the concepts of spacers, linkers, and tethers instead of the chain, where the spacer (or linker) has the function of separating, in a flexible fashion, the diene and the dienophile by the correct distance for accommodation into the requisite transition state conformation. The tether is perhaps the most common word used now, and includes the concept of the spacer together with more subtle details about functional groups present. The combination of the requisite distance together with the organisation of the tether into preferred conformations, can secure the diene and dienophile units into more tightly structured relationships and therefore more appropriate transition states. Finally, the tether can also include modifiers at the termini which are chosen and incorporated for the specific purpose of fine-tuning the electronic situation of the diene and/or dienophile.

Thus the concept of the tether can be conveniently subdivided into the following;

a) The tether is permanent in that it is to be used in the cycloaddition reaction and also is present in the product, with perhaps minor functional group modifications occurring after the IMDA reaction.

b) The tether is still permanent in that it also uses strong covalent bonds, and a portion will be retained in the product. The tether is also to be chosen for some steric effect, such as the tether control group effect ${ }^{34-36}$ or the buttressing effect $^{53}$, which are used to advantage to force the diene and dienophile groups into greater proximity.

c) The tether is less permanent and not to be used in the cycloadduct's further chemistry, as is the case with the protecting group strategy ${ }^{54}$ involving silyl ether tethers ${ }^{55-57}$.

d) The tether is temporary to the point of being created in situ during the reaction, leading to the transition state, and being removed from the cycloadduct at the end of the reaction.

\section{Tethers in IMDA Reactions}

In this section the more recent developments of tether applications in the IMDA reaction will be presented in the same sequence as outlined above.
The permanent type of tether is the dienophile linked to an electron withdrawing group, and then to the diene by a methylene chain, preferably with the functional groups which are present in the desired cycloadduct. The electron withdrawing group most frequently chosen is the carbonyl group (Scheme 13; equation 1), as a ketone or as an ester or amide. However, it is important to recognise that there is a big difference between ketones and the other two groups due to preferred conformational requirements of the ester and amide groups, with their heteroatom non-bonding electrons being in overlap with the p orbital of the carbonyl group.

Scheme 13 also shows some examples of this type of tether, as in the strained ester which joins a sterically hindered diene to an alkyne dienophile in the synthesis of an intermediate for the diterpene forskolin (Scheme 13; equation 2$)^{58}$. In this rather difficult IMDA reaction both the cycloaddition precursor and the cycloadduct suffer hydrogen shifts and other competing reactions, under the vigorous thermolytic conditions employed. Equation 3 demonstrates the use of a remote chiral auxiliary on the diene, through an ester chain to the maleate type dienophile, promoting the exo-transition state products with high diastereofacial selectivity ${ }^{59}$. The relatively simple amide cycloadduct shown in equation 4 is potentially useful for the synthesis of morphine analogues ${ }^{60}$, and a vinyl imidate IMDA reaction cycloadduct has been taken through to a yohimbane alkaloid (equation 5) ${ }^{61}$. The pyrone group acts as a masked diene in the IMDA reaction, which is then followed by loss of $\mathrm{CO}_{2}$ and direct re-aromatisation, leading to antitumor lycorine alkaloids (equation 6) ${ }^{62}$. Phenols can be ether linked to the diene component, oxidised to the corresponding parabenzoquinone mono-ketals which then undergo in situ IMDA reactions, to give cis-decalins fused to furan rings reminiscent of certain diterpenes (equation 7$)^{63}$.

Sulphones (Scheme 14; equation 1) ${ }^{64}$, sulphoximines (equation 2$)^{65}$ and vinyl sulphonates (equation 3$)^{66}$ have been shown to be excellent dienophile electron withdrawing groups, and their cycloadducts are clearly of synthetic relevance. An interesting sequence of pericyclic reactions includes a [3,3] sigmatropic rearrangement, COS extrusion to a sulfide chain and finally an IMDA reaction (Scheme 14 ; equation 4) leading preferably to cis-fused cycloadducts, and this selectivity is supported by ab initio calculations ${ }^{67}$. 


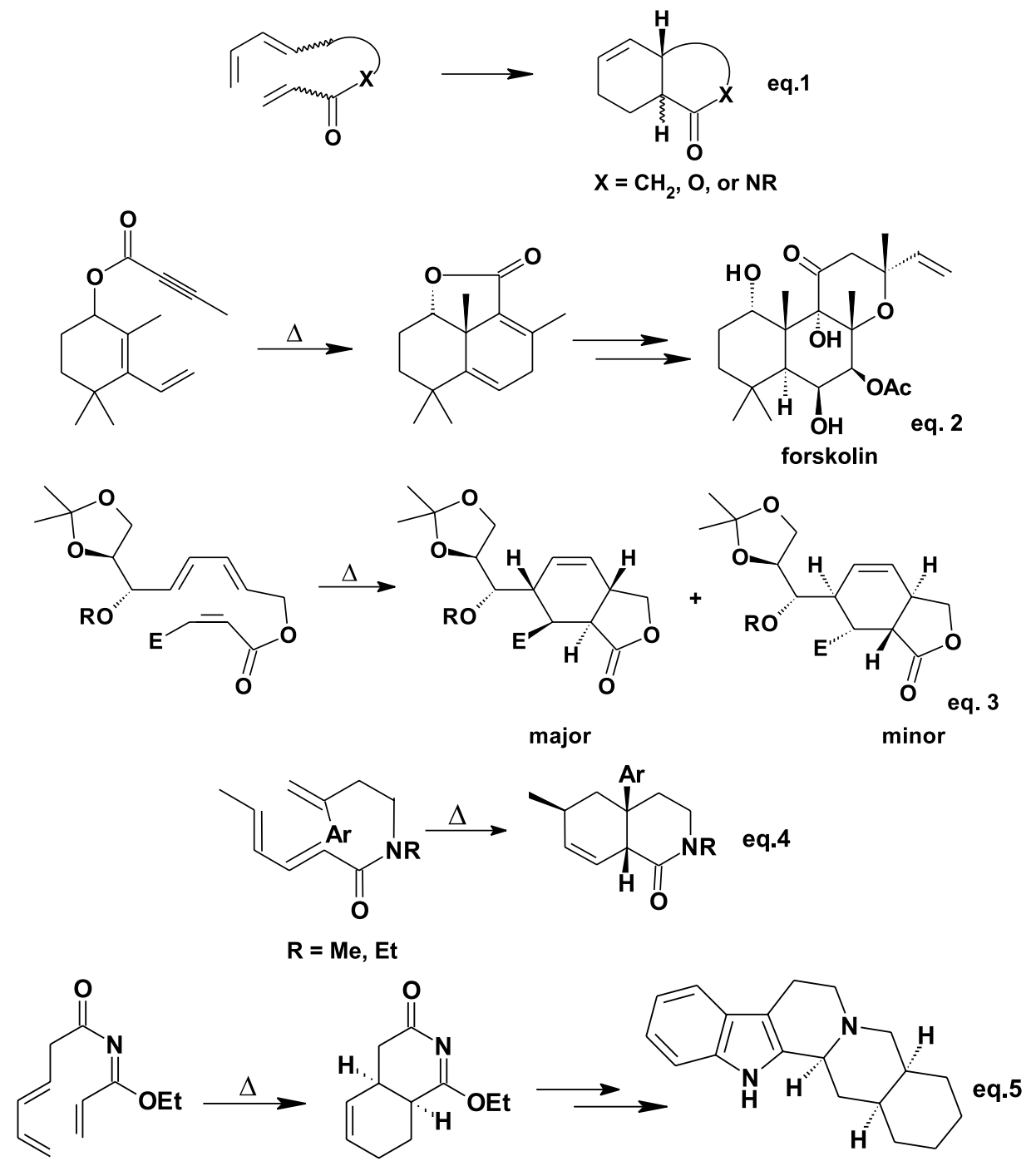

(土)-alloyohimbane<smiles>C#CCCn1c(=O)c2cc3c(cc2c2cc(F)c(=O)oc21)OCO3</smiles>

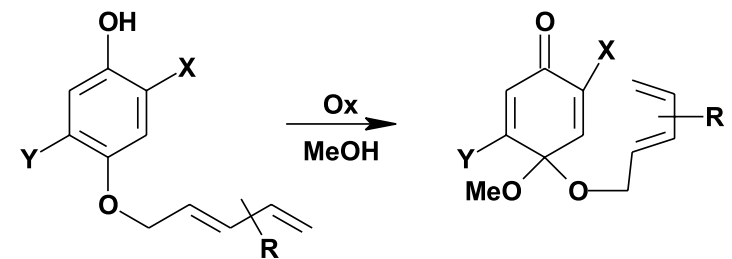

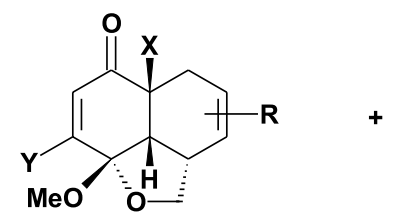

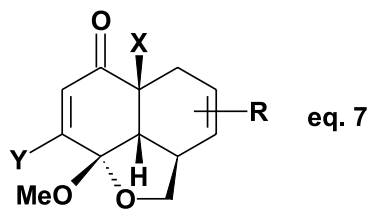

Scheme 13. 


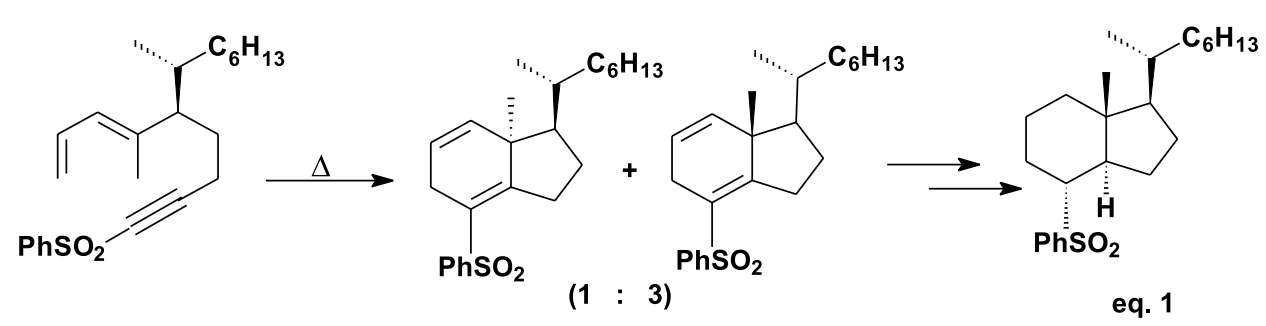<smiles>C/C=C\C=C/CCC/C=C/S(=N)(=O)c1ccccc1</smiles>

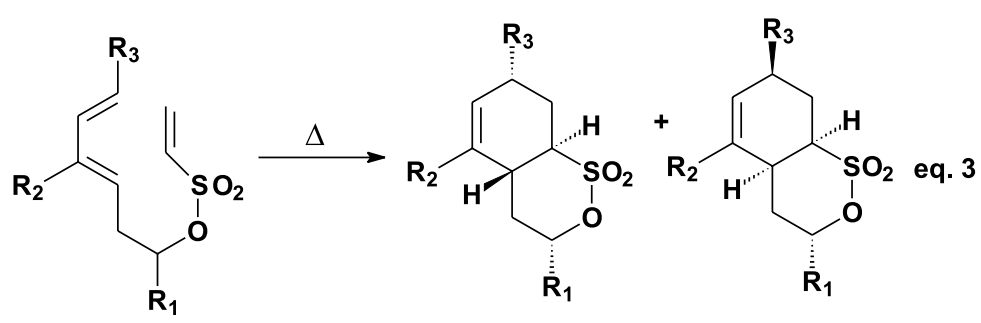<smiles>C/C=C/C=C\COC(=S)SC/C=C/C/C=C/F</smiles><smiles>C/C=C\C(=C/C)SC(=O)SC/C=C/C/C=C/F</smiles>

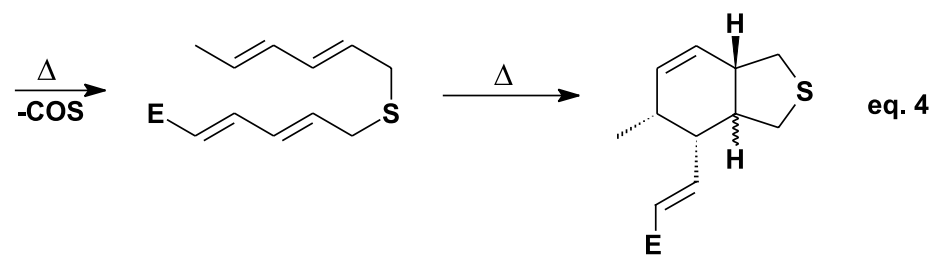

Scheme 14.

The bis-IMDA reaction has been effected under high dilution and with boron trifluoride etherate as Lewis acid catalyst (Scheme 15; equation 1) ${ }^{68}$, leading to a condensed policyclic carbon skeleton with two contiguous quaternary carbon atoms. The exo-methylene dienophile shown in equation 2 undergoes an IMDA reaction leading to a spiro structure, on a synthesis to an intermediate for the tetracyclic diterpene stemodin ${ }^{69}$.

The type II IMDA reaction has been studied by Shea and co-workers as an entry into cyclopentanes fused to medium rings, specially seven and eight membered, by oxidative cleavage of the cycloadduct and intramolecular aldol reaction ${ }^{70}$. They have pointed out the advantages of this approach, in which the rigid cycloadduct can be transformed with complete stereochemical control before the ring rearrangement occurs, and the new conformationally flexible medium ring is liberated (ledol synthesis; Scheme 16; equation 1). The extended type II IMDA reaction involves a bicyclic nucleus with the chain starting even further away from the diene thus creating larger medium rings (nine to eleven membered). The use of the 3 -sulpholene unit allows tandem extrusion of $\mathrm{SO}_{2}$ and IMDA reaction (Scheme 16; equation 2$)^{71}$. The synthesis of cytochalasin analogues requires the formation of an eleven membered ring, which 
<smiles>C=C/C=C\CCCC(=O)C#CCCC/C=C/C=C</smiles>

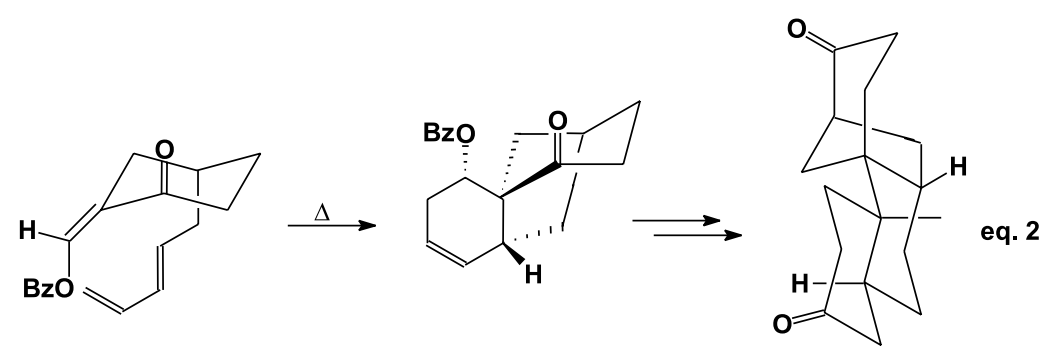

Scheme 15.
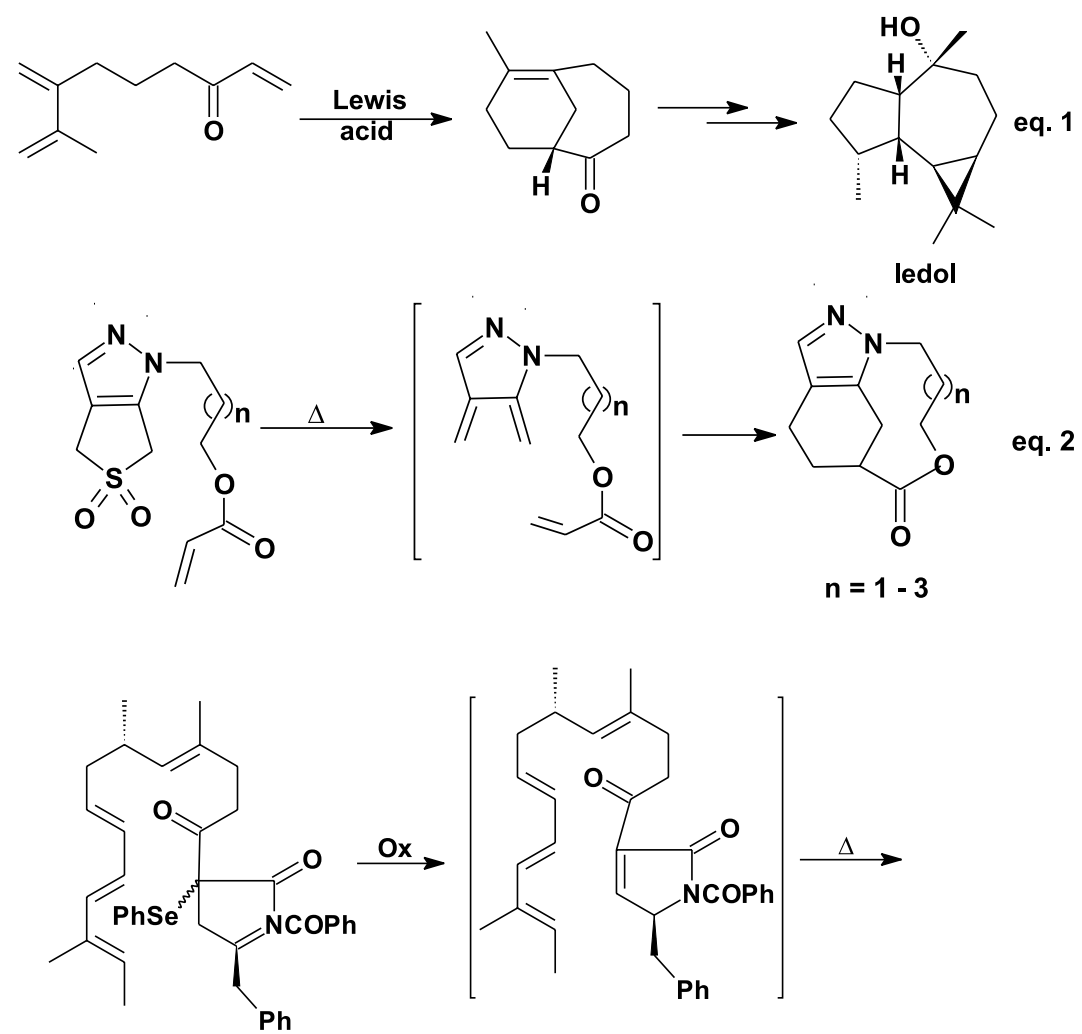

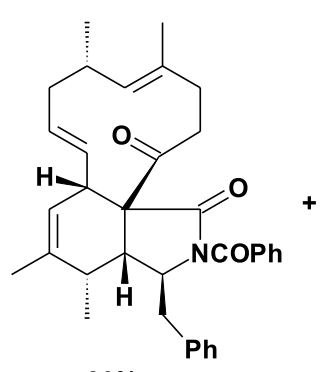

$30 \%$

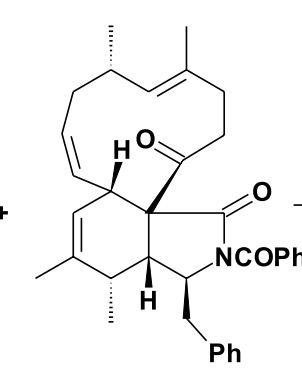

$4 \%$

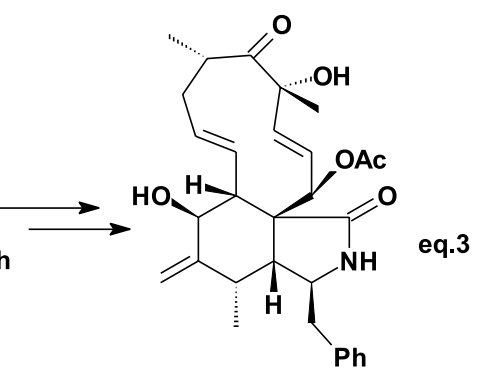

cytochalasin D 
can be successfully accomplished by the IMDA reaction after in situ oxidation of an $\alpha$-phenylselenenyl ketone to the enone dienophile. Although the yield is not very high, the IMDA reaction is noteworthy for its chemoselectivity towards the triene, and the endo transition state leading to the required stereochemistry (Scheme 16; equation 3$)^{72}$.

The second type of tether that has been developed more recently involves two different solutions to the same basic question of how to force the diene and dienophile components into closer proximity by the use of a steric control element. Scheme 17 (equation 1) presents the solution which Fallis and co-workers have named the tether control group ${ }^{34-36}$, and which works by incorporation of rigidity. This rigidity can be imposed on the tether by a simple cis-double bond or its di-hydroxyl derivatives, and also by different kinds of aromatic rings. The second solution involves the buttressing effect ${ }^{53}$ whereby a conveniently located quaternary carbon atom is substituted by the diene chain, the dienophile chain and two substituents which reduce the conformational liberties of the two chains. The exchange of simple methylene groups in the tether (group X) for more highly substituted carbon atoms has been studied (Scheme 17; equation 2) with convincing results as to the buttressing effect ${ }^{73}$.

The tether control group solution has been exhaustively explored by the Fallis group ${ }^{34-36}$ in their approaches to the taxoids. Other groups have also explored this strategy for taxol synthesis ${ }^{74,75}$ as shown in Scheme 18 (equations 1 and 2). The first example employs bicyclo [2.2.2] octene rigidity, whereas the second equation exploits the rigidity of a ring A degraded steroid nucleus. Similar advantages of cyclohexane dicarboxylic acid esters ${ }^{76}$ for the required control (equation 3), as well as the cyclohexenol skeleton ${ }^{77}$ for the synthesis of the sesterterpenoid dysidiolide (equation 4) can be seen in the two other examples in Scheme 18 .

The quaternary carbon buttressing effect is amply demonstrated in Scheme 19, as in the syntheses of the sesquiterpene bakkenolide-A (equation 1$)^{78}$, the sex pheromone homo-sesquiterpene 3-methyl- $\alpha$-himachalene (equation 2) ${ }^{79}$, a phorbol intermediate (equation 3$)^{80}$ and steroidal intermediates (equation 4) ${ }^{81}$. The latter example shows how the simple change from a ketone to an acetal can increase both the yield and the stereoselectivity of the thermal IMDA reaction.

The use of less permanent tethers such as silyl ethers has become important as can be judged by three recent reviews on this subject ${ }^{55-57}$, and Scheme 20 in which two examples are shown. The preparation of organosilanes is now quite common so that their coupling through silyl ether bonds is straightforward and allows IMDA reactions to proceed smoothly. The interesting aspect of the example shown in equation 1 has perhaps more to do with the bicyclopropylidene dienophile unit than the tether itself, and the fact that the reaction is conducted under very high pressure at $130{ }^{\circ} \mathrm{C}$ for twenty hours to give the cycloadduct in $83 \%$ yield $^{82}$. The Shea laboratory has been very prolific in this area, and the enantioselective synthesis of (+)adrenosterone by a double asymmetric induction IMDA reaction typifies their strategy (Scheme 20; equation 2$)^{83}$.

More recently these ideas have been extended to the interesting concept of the temporary tether, which is created during the reaction by consecutive treatment of the appropriate diene and dienophile with a readily available organometallic reagent. The metal template thus allows the IMDA reaction to occur due to the correct transition state geometry being elaborated, whereupon simple hydrolytic work-up releases the cycloadduct. The
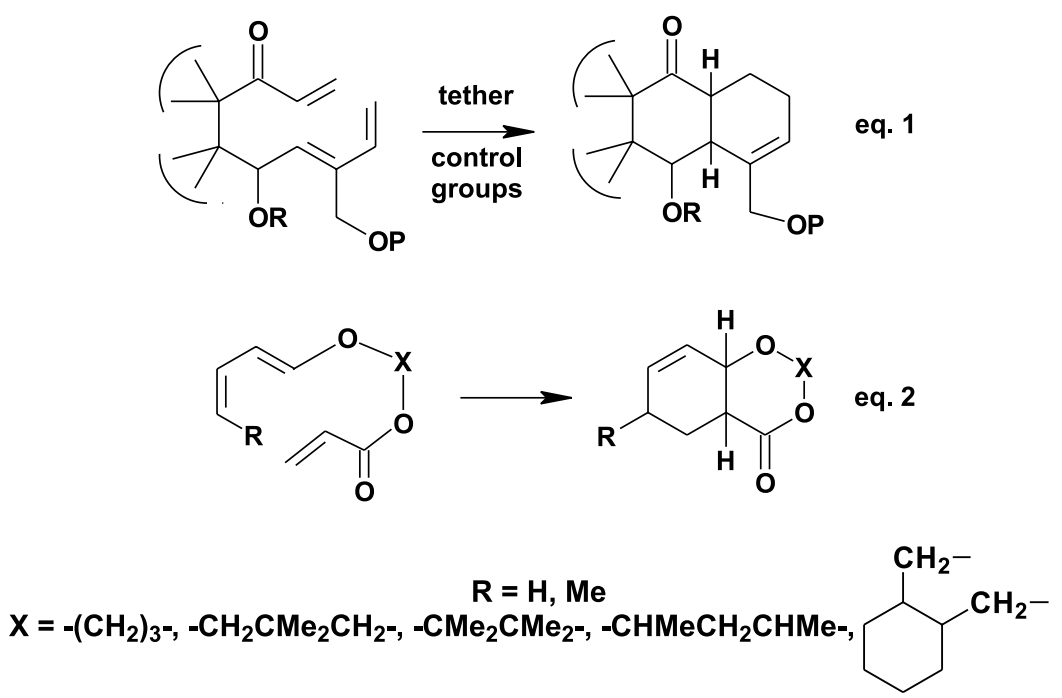

Scheme 17. 

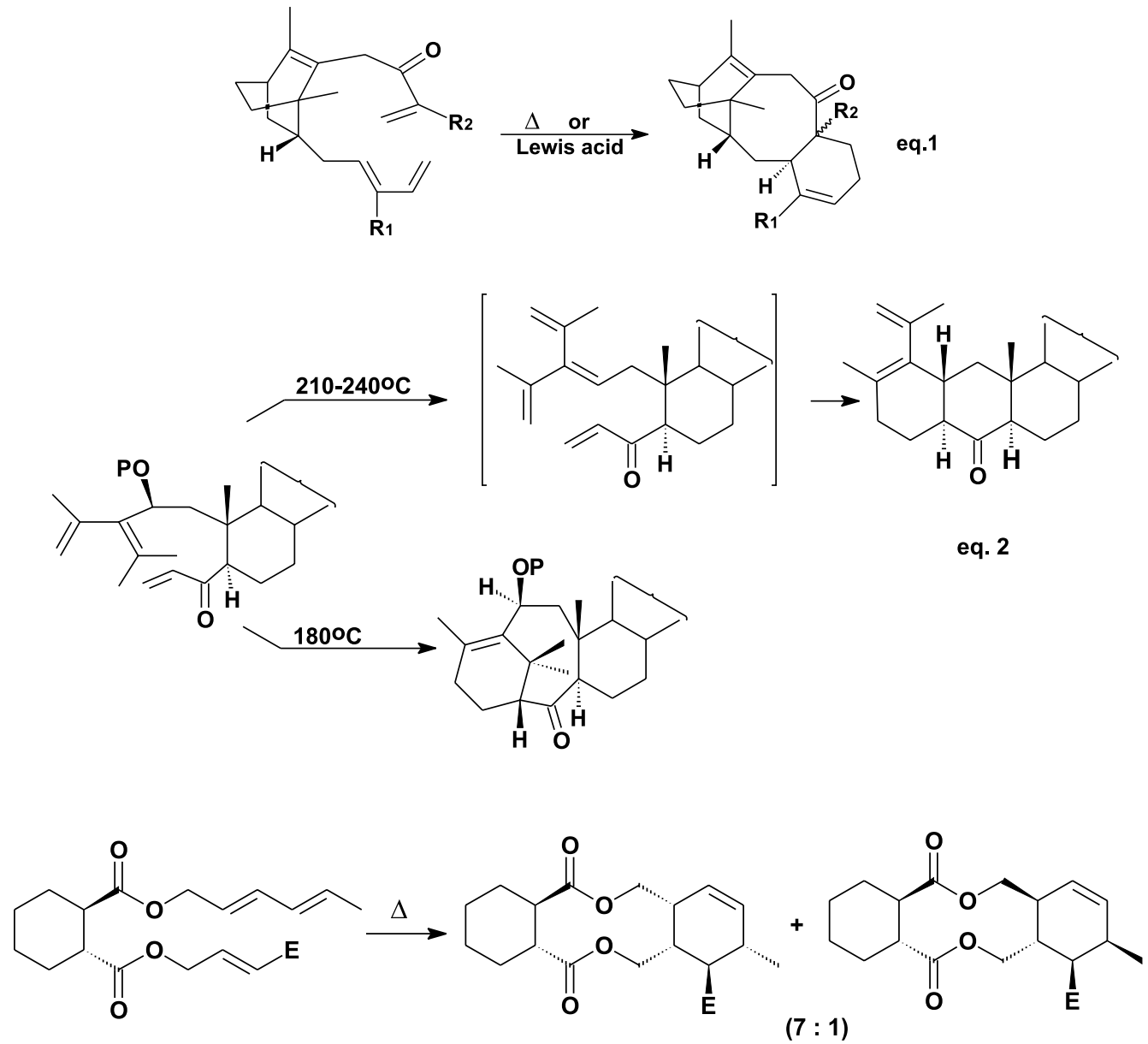<smiles>C/C=C/C=C/COC(=O)C1CCCCC1C(=O)OC/C=C/F</smiles>

eq. 3<smiles>COC[C@H]1[C@H](COC(=O)C2CCCCC2C(=O)O)C=C[C@@H](C)[C@H]1F</smiles>

$(1: 1)$<smiles>CC1(C)CCC(OC(=O)C#CC2CC2)C=C1CCS(=O)(=O)c1ccccc1</smiles>

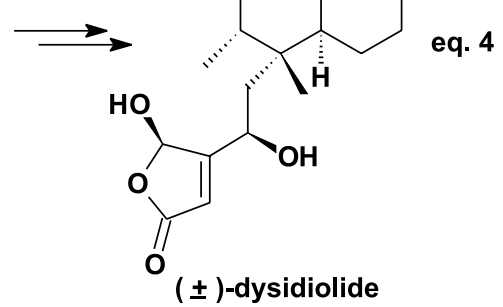

Scheme 18.

subtlety involved can be increased to the point where the organometallic reagent covalently binds to a suitable diene and simultaneously chelates with the dienophile component, allowing an organised transition state in which the dienophile chelation also lowers the activation energy for the process. Scheme 21 demonstrates this 


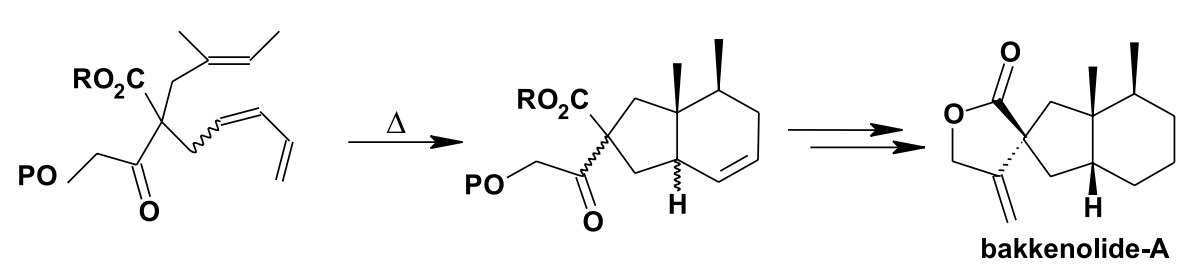

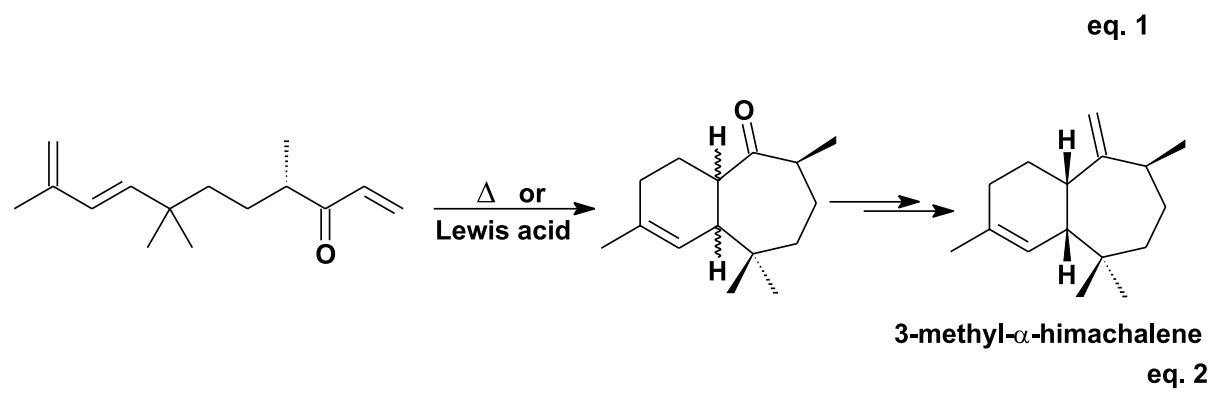<smiles>C=C/C=C\CC(F)(F)CC1C(C=C)CCC12OCCO2</smiles>

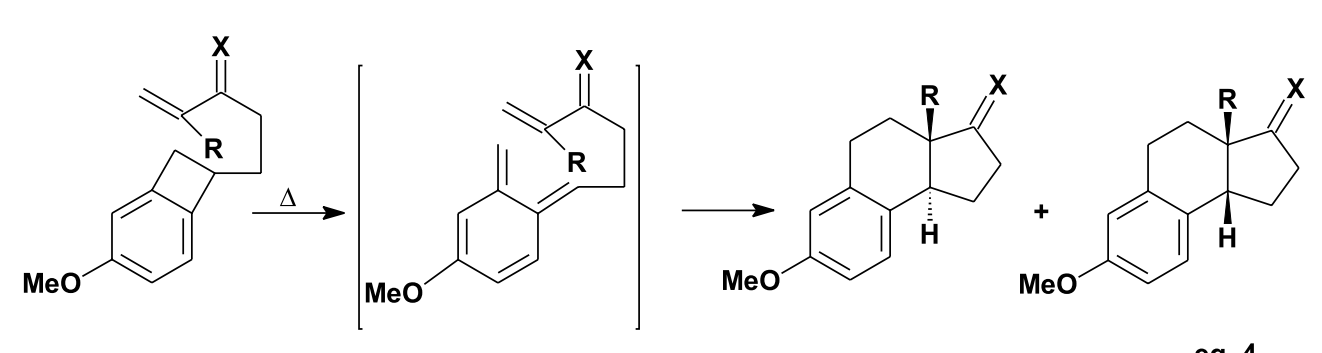

$\mathrm{X}=\mathrm{O}$ or $-\mathrm{O}\left(\mathrm{CH}_{2}\right)_{3} \mathrm{O}$ -

eq. 4

Scheme 19.

approach starting with the Stork laboratory use of organomagnesium complexes in IMDA reactions (equation 1), following their successful use of organosilanes, and also includes an organo-aluminium option ${ }^{84}$. Vinyl-boranes can be tethered to dienes and then undergo an IMDA reaction followed by conversion of the carbon-boron bond to more conventional functionality (equation 2$)^{85}$. Commercially available trialkylaluminium and dialkylzinc reagents can be reacted with suitable dienols and hydroxy-dienophiles to create metal template promoted IMDA reactions, whereupon simple hydrolytic work-up frees the dihydroxy-cycloadducts (equation 3) ${ }^{86}$. Methyl Grignard reagent can be reacted with the same dienols and then the magnesium atom chelated with the carbonyl of traditional dienophiles promoting selective IMDA reactions (equation 4$)^{87}$.
The IMDA Reaction in Total Synthesis

Many total syntheses now include at least one pericyclic reaction as a key step, preferably in a tandem combination with another pericyclic reaction, and where the Diels-Alder reaction is the most popular choice for the preparation of six membered rings. The many reasons for this have been outlined already in this review, and a few examples have been chosen to finish off this section. The Evans group has used the IMDA reaction both in total synthesis and as a vehicle for demonstrating the success of bis-oxazoline chiral catalysis, as for example in generating the hydrindene nucleus of more complex natural products (Scheme 22, equations 1 and 2) ${ }^{88,89}$. The metabolite VM55599 has been synthesised by an aza-dienone to terminal alkene IMDA reaction, and further simple manipulations (equation 3$)^{21}$. 

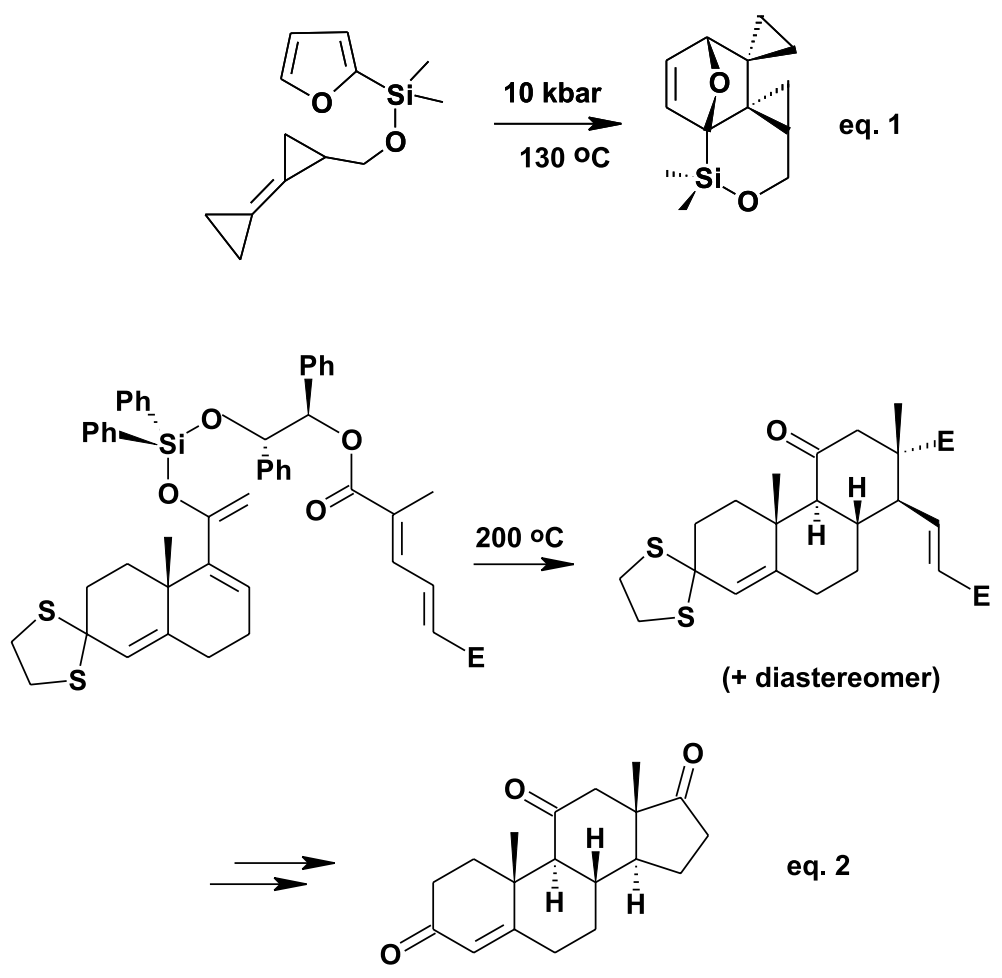

(+)- adrenosterone

Scheme 20.

The lovastatin group of fungal metabolites can be synthesised by way of an IMDA reaction ${ }^{90}$, and this has been proposed as being an important biosynthetic process ${ }^{23}$ which can be simulated in the laboratory (Scheme 22; equation 4). The mniopetal group of drimane sesquiterpenes has been the synthetic objective of at least two groups ${ }^{91,92}$, as can be exemplified in Scheme 22 (equation 5). (+)-Quassin has been synthesised ${ }^{93}$ starting from (S)-(+)-carvone, appropriately alkylated to a 3-sulpholene derivative which extrudes $\mathrm{SO}_{2}$ and undergoes an IMDA reaction, in an approach which is quite similar to that used by the Abad group (scheme 4; equation 1$)^{37}$. The cycloadduct then suffers many transformations before producing the desired quassin, as shown in Scheme 22 (equation 6). The Hudlicky group has made excellent use of the chiral and enantiopure dihydroxycyclohexadienes obtained by microbiological oxidation of simple benzenes, and among many interesting syntheses have looked at the coupling of these diene-1,2-diols with appropriate dienophiles for IMDA reactions. The example in scheme 22 (equation 7) ${ }^{94}$ involves a chemoselective IMDA reaction followed by a [3,3] sigmatropic rearrangement, thus leading to an angularly methylated cis-decalin furan skeleton.

Scheme 23 illustrates some novel applications of the IMDA reaction which cannot be conveniently classified in the preceding sections. Rawal and co-workers ${ }^{95}$ have used an interesting expedient with less reactive conjugated cycloalkenones, containing a diene tether at the 4- position, by photochemically isomerising the $Z$-enones to the much more reactive trans-enones, and thus producing policyclic structures of different stereochemistries (Scheme 23; equation 1). Iminium salts undergo IMDA reactions in aqueous medium in the presence of strong acids to produce tricyclic piperidine structures (equation 2$)^{96}$. The dienophile partner can be suitably activated by metal complexes as has been shown with the metal (chromium, molybdenum or tungsten) carbene complexes shown below (Scheme 23; equation 3$)^{97}$. Both the IMDA and TADA reactions can be initiated by radicals as has been demonstrated by the Malacria ${ }^{98}$ and Pattenden ${ }^{99}$ groups (Scheme 23; equations 4 and 5).

\section{The TADA Variation}

A more sophisticated version of the IMDA reaction has been developed, and is known as the transannular DielsAlder (TADA) reaction ${ }^{100,101}$. In the period under review (1990 to the present) about 60 papers have appeared in the literature dealing directly with the TADA reaction in synthesis, with the great majority coming from 


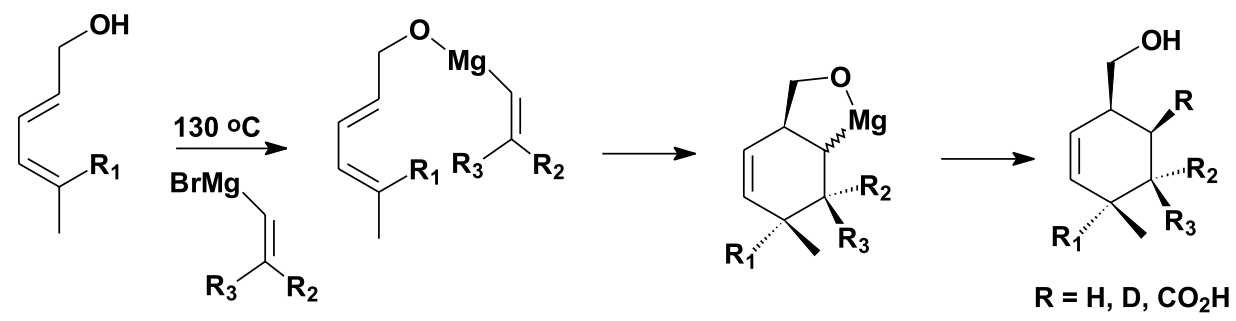<smiles>[R]C1CC(C)C=C(C=CC(=O)O)C1CO</smiles>

eq. 1

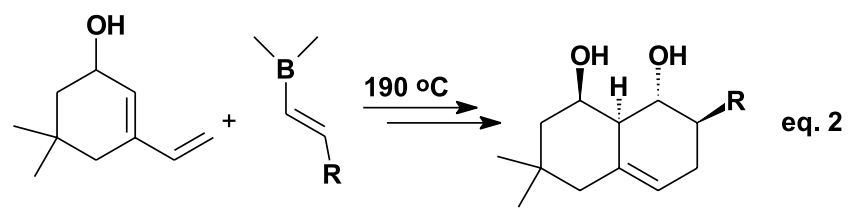<smiles>[R2]C=CC([R12])ON(C)OC/C=C(/C)C(C)C(C)C(C)C</smiles>

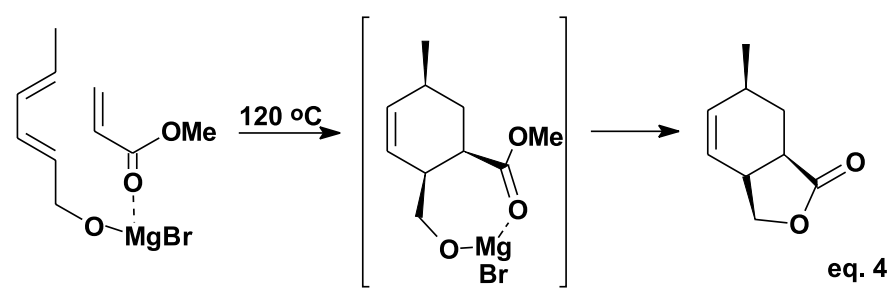

Scheme 21.

Deslongchamps' laboratory. This variation involves the construction of a macrocyclic molecule containing the diene and dienophile moieties, in which the conformational mobility permits approximation of the two reactant units, whereupon the TADA reaction may occur to produce a highly complex polycyclic structure with complete control of chemo-, regio- and stereoselectivity at both the diastereoand enantioselective levels. Clearly the synthetic challenge here is in the construction of the requisite macrocyclic precursor, and effective molecular modelling on the future transition state. The synthetic problems include the correct diene and dienophile stereochemistries of the linear triene, the macrocyclisation reaction, the TADA reaction itself, and competing [1,5] hydrogen shifts ${ }^{100-102}$ and transannular Alder-ene reactions ${ }^{100,101}$. The triene $\mathrm{sp}^{2}$ carbon stereochemistries are transformed into the four $\mathrm{sp}^{3}$ carbon stereogenic centres at the ring junctions during the cycloaddition reaction, as can be exemplified in Scheme 24.

The TADA reaction has been most frequently studied with 13,14 and 15 membered macrocycles, under 


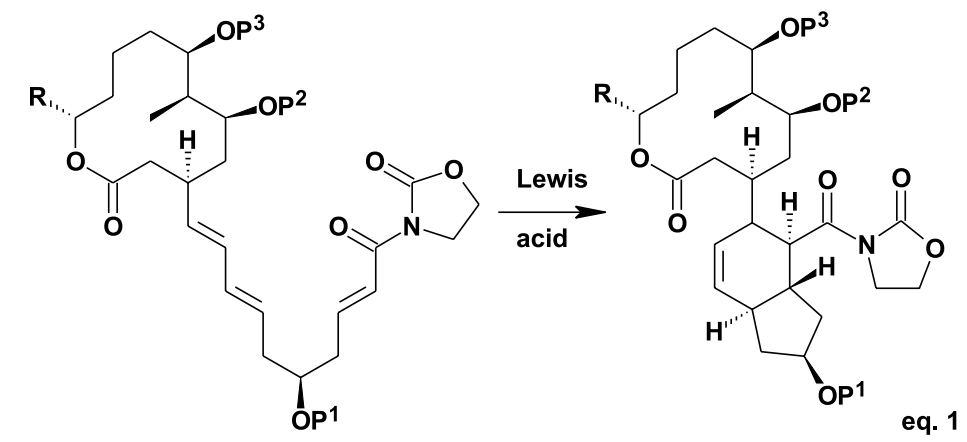<smiles>[R]C=C/C=C\C[AlH2]C/C=C/C(=O)N1CCOC1=O</smiles>
$n=1,2$<smiles>[R]C1C=C[C@H]2C[Al]C[C@]2(CC)C1[C@H](C(=O)N1CCOC1=O)C(C)(C)C</smiles><smiles>C=CC(C)(C)c1[nH]c2ccccc2c1Cc1nc(OC)c2n(c1=O)CC[C@H]2C</smiles><smiles>C[C@@H]1CCN2C[C@]13C[C@H]1C(C)(C)c4[nH]c5ccccc5c4CC1(C2=O)N3C</smiles>

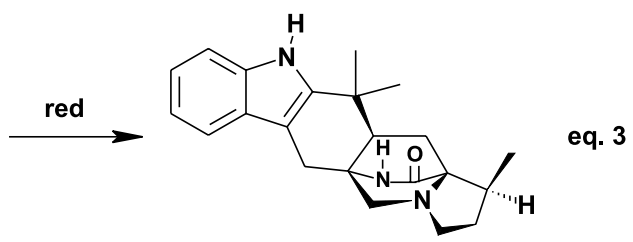

VM55599

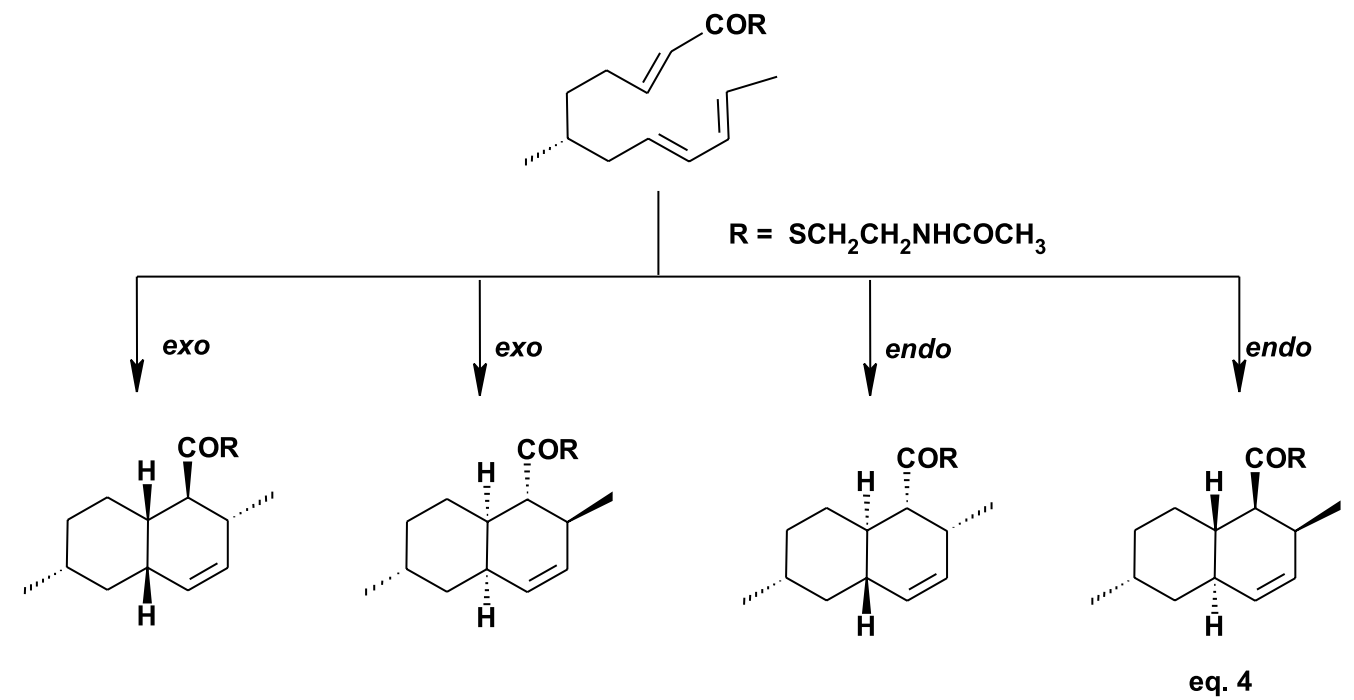

Scheme 22. 


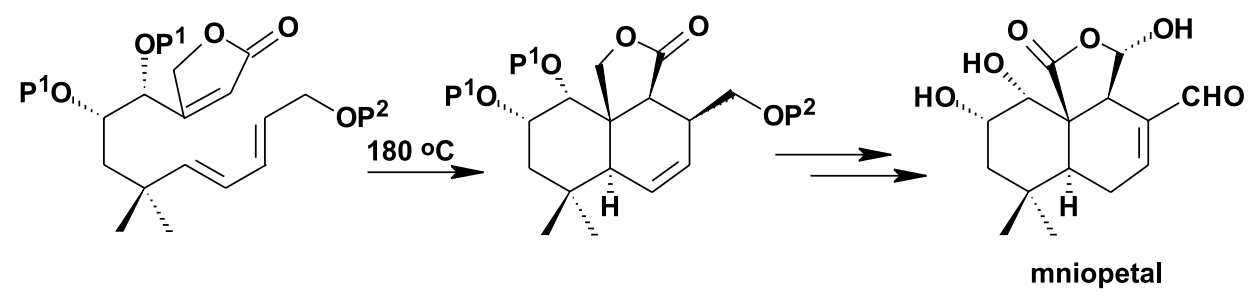

eq. 5

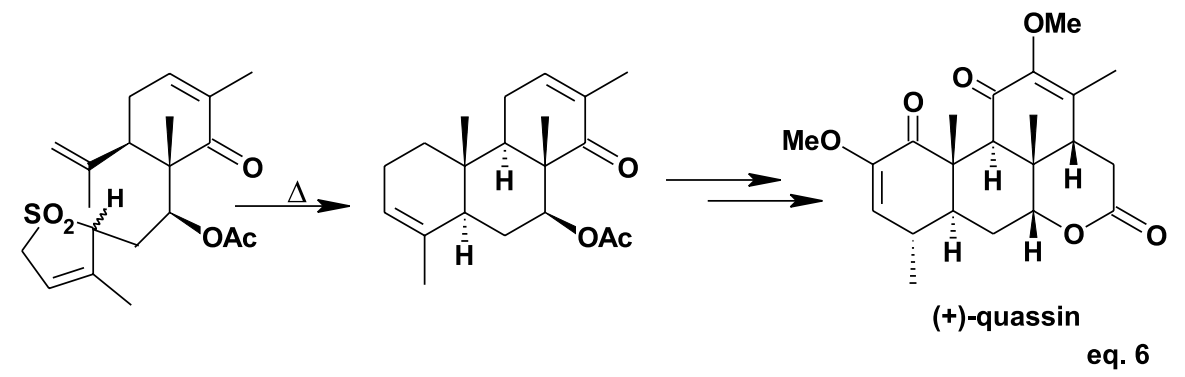

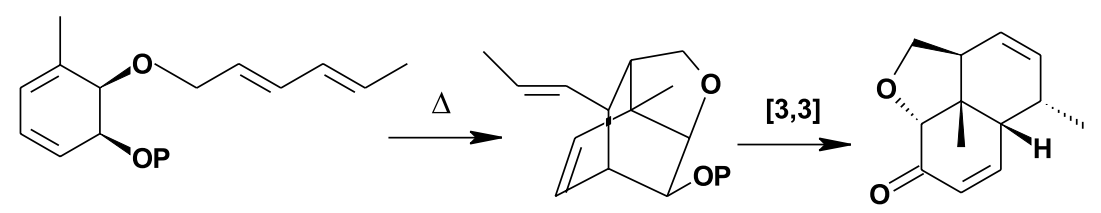

eq. 7

Scheme 22. (cont.)

thermolytic reaction conditions but also with studies on the effects of Lewis acids and high pressures. The rigorous thermolytic conditions ( 200 to over $300^{\circ} \mathrm{C}$ ) sometimes used, provoke competitive $[1,5]$ hydrogen shifts producing new dienes which can also undergo the TADA reaction, thus creating complex mixtures of cycloadducts. This facet of the TADA reaction has been thoroughly demonstrated experimentally, and accompanied by extensive semiempirical calculations ${ }^{102}$. The use of Lewis acid catalysis is rewarding as the much lower temperatures inhibit the hydrogen shifts, and do not induce Alder-ene rearrangements of the $\mathrm{C}=\mathrm{C}$ enophiles. The commentaries made above on steric and electronic effects, selectivities, and tethers are just as relevant for the TADA as for the IMDA reaction, with the added aspect of the even more restricted conformational mobility which should be explored to advantage.

To illustrate the enormous potential of the TADA reaction a few recent examples from the Deslongchamps laboratory will be discussed first. The synthesis of steroid compounds is illustrated in Scheme 25, involving the macrocyclisation of an open triene under high dilution conditions to the requisite precursor, and a high temperature TADA reaction furnishing stereoselectively a tetracyclic intermediate. Standard reactions then lead to an analogue of aldosterone ${ }^{103}$. In this study, and a related investigation ${ }^{104}$, extensive use of molecular modelling was elucidative for rationalising the experimental results.

The tetracyclic diterpenes chatancin and sarcophytin are the objects of the TADA approach by way of biosynthetic analogies ${ }^{105-107}$ as can be seen in Scheme 26. In this approach, the open triene substrate is constructed from a geraniol derivative, cyclises under standard high dilution conditions and then undergoes the TADA reaction to furnish two diastereomeric tetracyclic products of advanced similarity to the natural products. The TADA reaction deserves comment in that the dienophile is unactivated, and reacts with a furan system in a high yielding manner. However, the ratio of the two diastereomers formed demonstrates a large solvent effect on changing from toluene (reflux for $48 \mathrm{~h}$, condition a, 93\%) to an aqueous DMSO system (DMSO/ $\mathrm{H}_{2} \mathrm{O} 1: 2,105^{\circ} \mathrm{C}$ for 50h, condition b, 80\%).

Another tetracyclic diterpene is accessible through a tandem TADA-aldol sequence (Scheme 27), in which a fifteen membered ring is formed from a suitable enantiopure triene. The double cyclisation takes place upon 

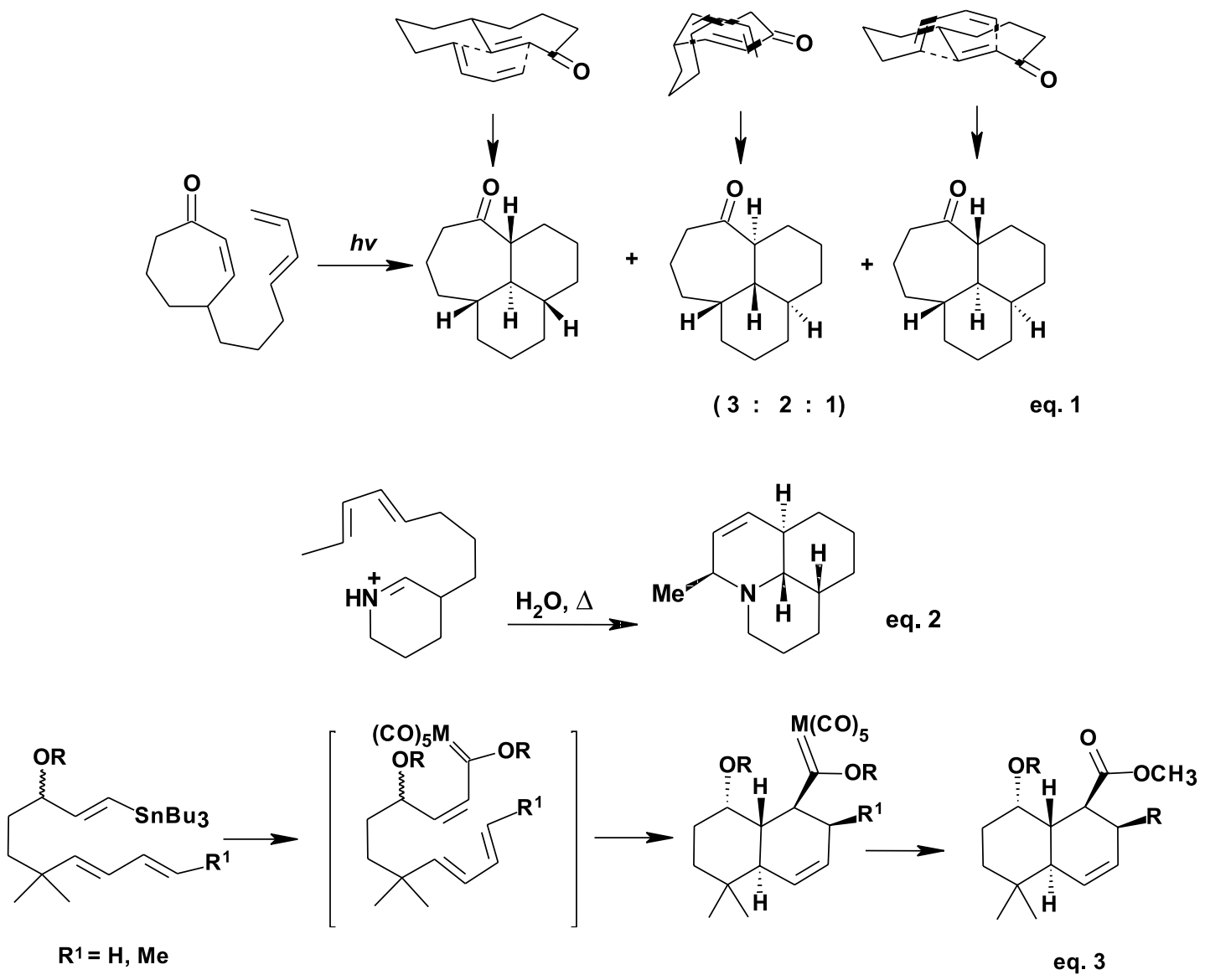<smiles>C#CCC(F)(F)CC(C)CCCCCCC=CCF</smiles>

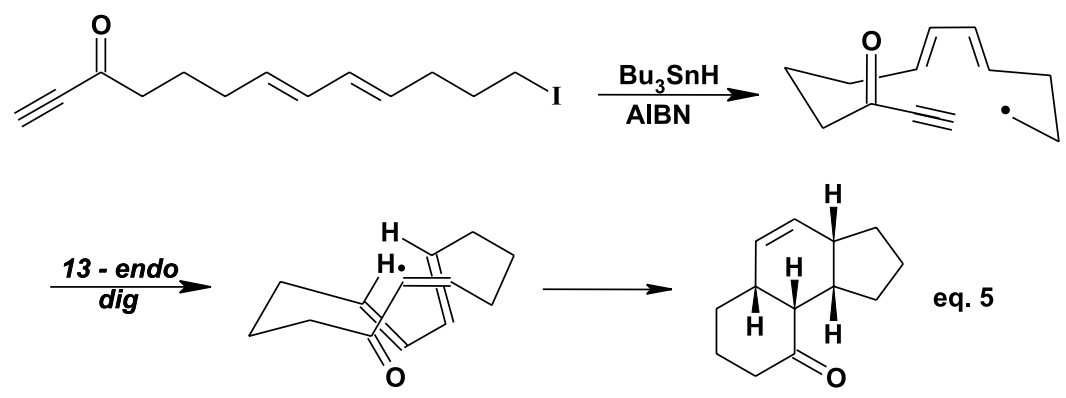

Scheme 23. 


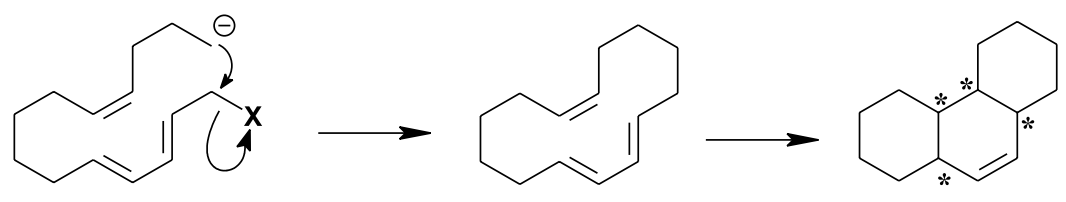

Scheme 24.<smiles>[R]C(=CC(=O)CCl)CCC(F)(F)CC=CC=CC1CCC(=O)[C@@H]1F</smiles>

Scheme 25.<smiles>[R6][C@H](c1oc(CCl)cc1F)[C@@H](C(C)C)[C@@H](C)CC/C=C(\C)CCC(F)C(F)F</smiles>

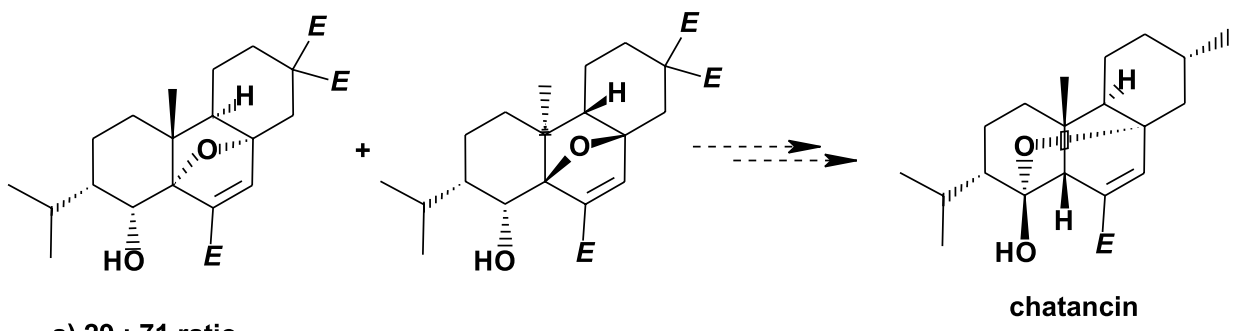

b) $90: 10$ ratio

Scheme 26.

thermolysis at $230{ }^{\circ} \mathrm{C}$ in the presence of triethylamine. A rather lengthy sequence of standard reactions then leads to (-)-8-epi-11-hydroxyaphidicolin containing an interesting $6,6,7$ ring system ${ }^{108}$.

Shing and Yang ${ }^{109}$ have effected the synthesis of (-)oblongolide by both IMDA and TADA reactions (Scheme $28)$. The requisite triene was readily prepared from (-)citronellol in five steps, and underwent an IMDA reaction at $210^{\circ} \mathrm{C}$ for 76 hours to give natural oblongolide in an overall $13 \%$ yield. The same triene gave poor yields of the macrolactone prepared by the Yamaguchi methodology in $27 \%$ yield but underwent a smooth TADA reaction in $80 \%$ yield by refluxing in toluene for 25 hours. An important aspect is due to the fact that the IMDA reaction is reversible. Thus if the desired product is kinetically unfavoured, an increase in yield might be attainable upon an increase in the reaction temperature.

Finally, Roush and co-workers have developed an efficient route to the antibiotic nargenicin's carbon skeleton by TADA reaction of an eighteen membered macrolide ${ }^{19}$, 


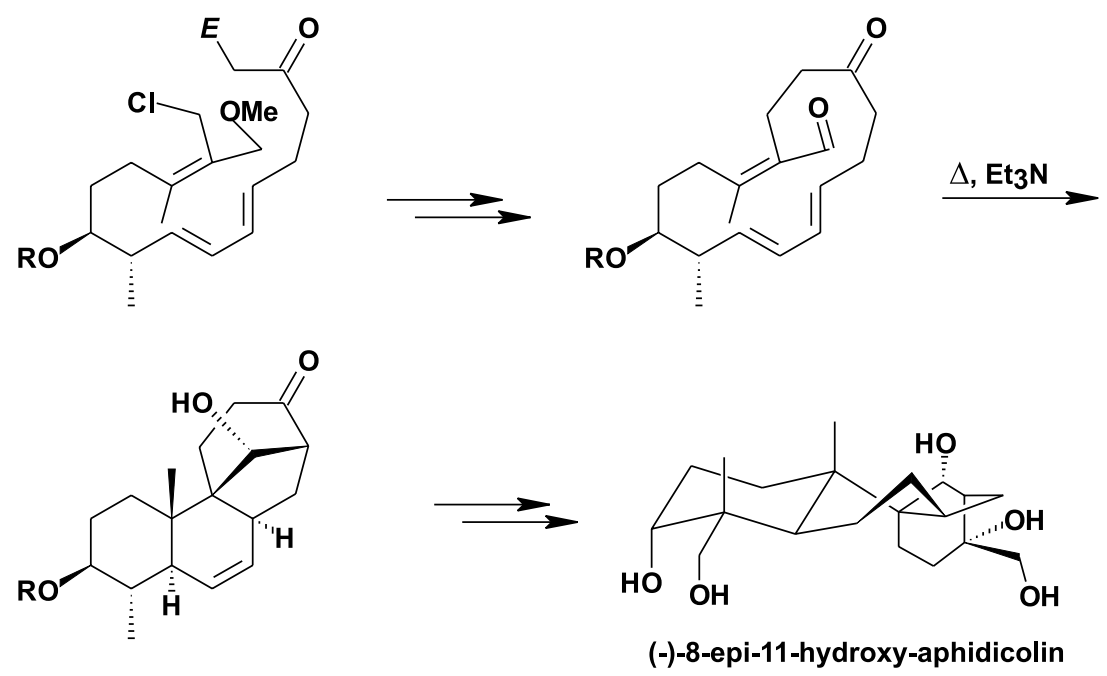

Scheme 27.<smiles>CC(=O)OC(C)=CCCC(C)CCC=CCO</smiles>

$210 \circ \mathrm{C}$<smiles>CC1C=C[C@H]2[C@@H](CC1)C(C)C[C@H]1COC(=O)[C@@H]12</smiles>

(-)-oblongolide<smiles>CCCCC=C(C)C(=O)O</smiles><smiles>CC(C)C/C=C\COC(=O)C(C)CC/C=C\CCC(C)C</smiles>

Scheme 28.

based upon a biosynthetic analogy involving an IMDA reaction and ten membered macrolactonisation. The TADA reaction is more selective and higher yielding than comparative IMDA reactions on similar substrates (nodusmicin synthesis, Scheme 29; equation 1). The synthesis also illustrates the relative ease of cyclisation to an eighteen membered lactone, as opposed to the well known difficulty of the ten membered lactone, thus constituting a formal ring contraction strategy. By a similar ring contraction followed by TADA reaction strategy perhydro-indacenes can be synthesised, whereby a sixteen membered ring lactone undergoes the Ireland-Claisen rearrangement and ring contracts into a twelve membered all carbon macrocycle ideal for in situ TADA reaction (Scheme 29; equation 2) ${ }^{110}$.
It is clear that the TADA approach permits a very high increase of molecular complexity during the macrocyclisation and subsequent cycloaddition, and depends only upon the ease of stereoselective triene macrocycle synthesis which has also undergone tremendous developments in the last two or three decades ${ }^{111-120}$. In this respect the macrocycle can be envisaged in two quite different forms, being a macrocycle of carbon atoms or a macrolactone or macrolactam system. As the latter have been the object of much research due to the plethora of macrocyclic antibiotic structures, there is presently perhaps more facility for their synthesis. This can then be coupled with Marshall's macrocycle ether to carbon macrocycle transformation via the Wittig $[2,3]$ sigmatropic rearrangement ${ }^{121}$, or the Ireland-Claisen rearrangement of macrolactones into carbon macrocycles ${ }^{110}$. 


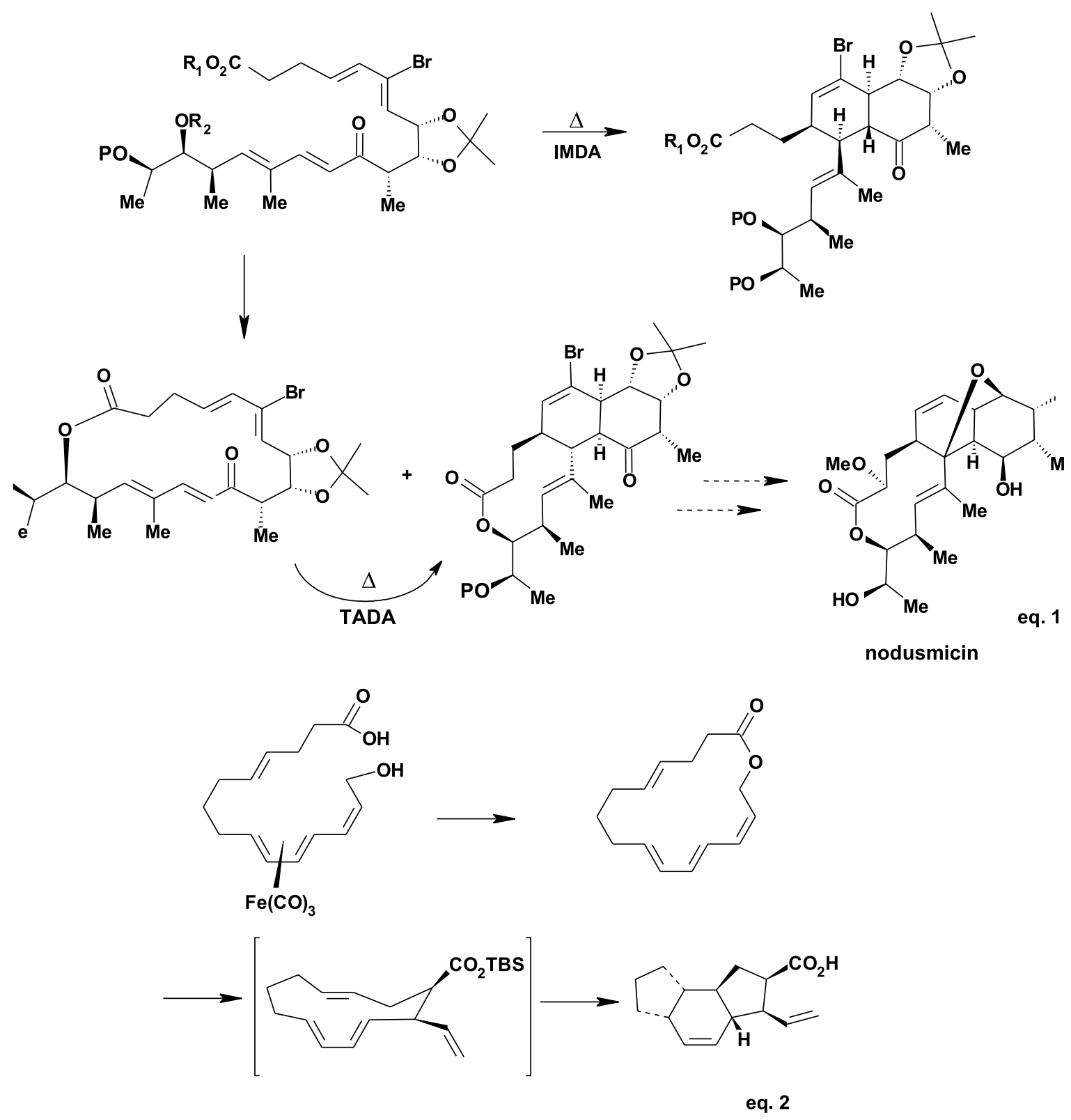

Scheme 29.

\section{Conclusion and Perspectives}

The intermolecular Diels-Alder reaction is now routinely performed at the highest selectivity levels by way of chiral and enantiopure dienes and or dienophiles, or on chiral auxiliaries, or by enantiopure Lewis acid catalysis. The same strategies are being applied to the IMDA reaction, as well as the use of chiral and enantiopure chain tethers. The level of control now available for the Diels-Alder reaction is demonstrated, suggesting that we can now choose our diene and dienophile components with great predictability as to the results of the cyclization. The correct form of bringing these two partners into cycloaddition in a high yielding, highly selective fashion and within the context of easy experimental conditions, is also demonstrated. The concerted but asynchronous nature of the intermolecular Diels-Alder reaction has long been recognised $^{122,123}$, and for the IMDA version leads to a premise in which the internal new carbon-carbon bond may be formed first, and therefore these two interacting carbon atoms must approximate within bonding distance. The opposite premise, of the external carbon-carbon bond being formed first, cannot be dismissed and can also be modelled before definitive tether groupings are proposed. The chain tether spacer must be planned with respect to the desired polycyclic product structure, but maintaining as the first 


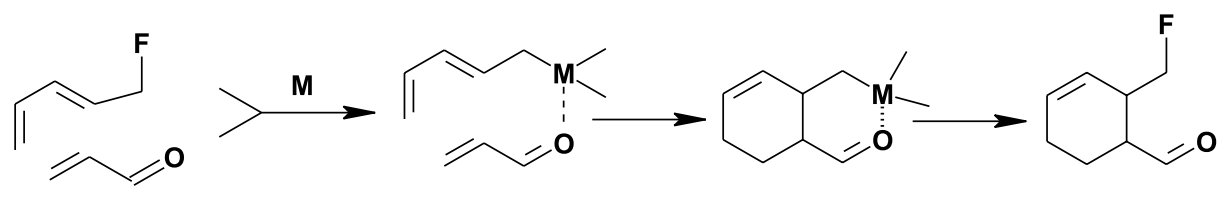

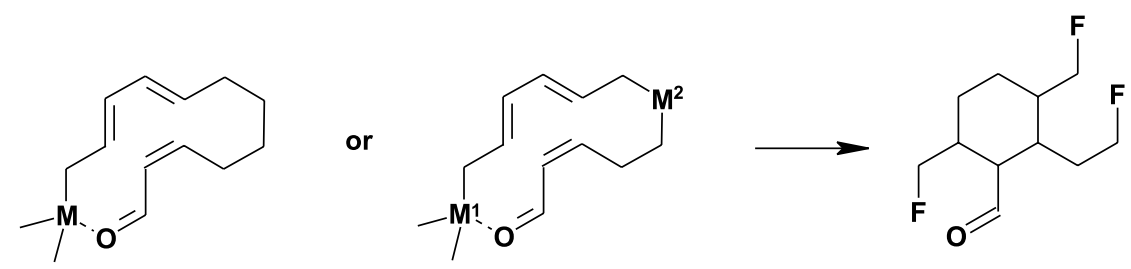

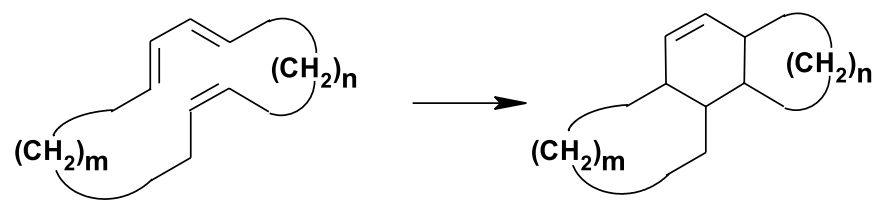

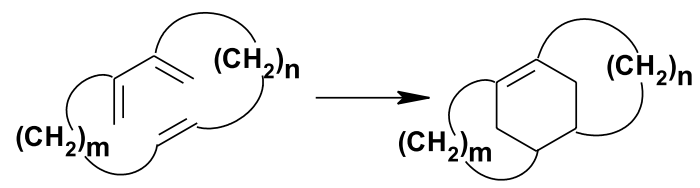

determining factor the electronic, steric and stereoelectronic requirements of the transition state. A similar conclusion can be advanced for the TADA reaction with respect to experimental ease, choice of tethers, and selectivities on to enantioselectivity.

The perspectives for the IMDA reaction are really quite impressive as one can predict the use of temporary tethers based upon organometallic reagents which simultaneously complex the diene and the dienophile as a Lewis base, creating a sufficiently low activation energy for a room temperature high yielding process to be executed in a couple of hours. Simple extractive isolation then leads to the product. The Lewis acid type organometallic reagent links the diene and dienophile partners as two ligands, leaving room for chiral and enantiopure ligands to occupy the other sites on the metal, thus leading to a highly enantioselective one-pot version (Scheme 30).

The TADA version as presently executed will probably pass through similar flights of imagination leading to temporary linking at one or both sides to emulate the perspective presented for the IMDA reaction (Scheme 30). The application of the type II IMDA reaction to the TADA variation should lead to the formation of varying medium sized rings coupled to the central cyclohexene nucleus.

\section{Acknowledgements}

The authors wish to acknowledge financial support from the following agencies: FAPESP, CAPES and CNPq. We also thank Tiago Moda for help with the preparation of the manuscript.

\section{Note added in Proof}

Since the submission of the manuscript the following publications have appeared: reviews on the Type II IMDA ${ }^{124}$ and the TADA ${ }^{125}$ reactions, as well as full papers on dysidiolide synthesis (Scheme 18; equation 4) ${ }^{126}, 1,3,8$ nonatriene IMDA reactions (Scheme 11; equation 2) ) $^{127}$ and bakkenolide synthesis (Scheme 19; equation 1) ${ }^{128}$. A report on the Pacifichem 2000 meeting highlights new annulation strategies, in which tandem pericyclic reactions including at least one [4+2] cycloaddition are very important ${ }^{129}$. The kinetic preference for the endo over the exo transition state 
is due to secondary orbital interactions, or should other well known mechanisms be invoked ? ${ }^{130}$

\section{References}

1. Carruthers, W. Cycloaddition Reactions in Organic Synthesis, Pergamon, Oxford, 1990.

2. Fringuelli, F.; Taticchi, A. Dienes in the Diels-Alder Reaction, Wiley-Interscience, New York, 1990.

3. Oppolzer, W. In Comprehensive Organic Synthesis: Trost, B. M.; Fleming, I., Eds.; Pergamon, Oxford, 1991, Vol. 5, pp. 315-399.

4. Fleming, I. Pericyclic Reactions, University Press, Oxford, 1999.

5. Fleming, I. Frontier Orbitals and Organic Chemical Reactions, J. Wiley, London, 1976.

6. Spino, C. Some Features of [4+2]- and [2+2]-Cycloadditions, Revised Edition, EdUFSCar, São Carlos, Brazil, 2001.

7. Corey, E. J.; Cheng, X-M. The Logic of Organic Synthesis, J. Wiley, New York, 1989.

8. Pindur, U.; Lutz, G.; Otto, C. Chem. Rev. 1993, 93, 741-761.

9. Dell, C. P. J. Chem. Soc., Perkin Trans. 1 1998, 38733905.

10. Varner, M. A.; Grossman, R. B. Tetrahedron 1999, 55, 13867-13886.

11. Hartley, R. C.; Caldwell, S. T. J. Chem. Soc., Perkin Trans 1 2000, 477-501.

12. Harmata, M. Tetrahedron 1997, 53, 6235-6280.

13. Winkler, J. D. Chem. Rev., 1996, 96, 167-176.

14. Houk, K. N.; Gonzalez, J.; Li, Y. Acc. Chem. Res. 1995, 28, 81-90.

15. Chen, J.; Deng, Q.; Wang, R.; Houk, K. N.; Hilvert, D. ChemBioChem 2000, 1, 255-261.

16. Tantillo, D. J.; Houk, K. N.; Jung, M. E. J. Org. Chem. 2001, 66, 1938-1940.

17. Bandaranayake, W. M.; Banfield, J. E.; Black, D. St. C. J. Chem. Soc., Chem. Commun. 1980, 902-903.

18. Nicolaou, K. C.; Petasis, N. A. In Strategies and Tactics in Organic Synthesis, Ed. Lindberg, T. chapter 6 Academic, 1984.

19. Roush, W. R.; Koyama, K.; Curtin, M. L.; Moriarty, K. J. J. Am. Chem. Soc. 1996, 118, 7502-7512.

20. Oikawa, H.; Kobayashi, T.; Katayama, K.; Suzuki, Y.; Ichihara, A. J. Org. Chem. 1998, 63, 8748-8756.

21. Stocking, E. M.; Sanz-Cervera, J. F.; Williams, R. M. J. Am. Chem. Soc. 2000, 122, 1675-1683.

22. Wallace, G. A.; Heathcock, C. H. J. Org. Chem. 2001, $66,450-454$.
23. Auclair, K.; Sutherland, A.; Kennedy, J.; Witter, D. J.; Van den Heever, J. P.; Hutchinson, C. R.; Vederas, J. C. J. Am. Chem. Soc. 2000, 122, 11519-11520.

24. Laschat, S. Angew. Chem. Intl. Ed. Engl. 1996, 35, 289-291.

25. Klunder, A. J. H.; Zhu, J.; Zwanenburg, B. Chem. Rev. 1999, 99, 1163-1190.

26. Tanaka, H.; Kamikubo, T.; Yoshida, N.; Sakagami, H.; Taniguchi, T.; Ogasawara, K. Org. Lett. 2001, 3, 679-681.

27. Banwell, M.; Hockless, D.; Jarrott, B.; Kelly, B.; Knill, A.; Longmore, R.; Simpson, G. J. Chem. Soc., Perkin Trans. 1 2000, 3555-3558.

28. Dias, L. C. J. Braz. Chem. Soc. 1997, 8, 289-332.

29. Fallis, A. G. Can. J. Chem. 1984, 62, 183-234.

30. Taber, D. F. Intramolecular Diels-Alder and Alder Ene Reactions, Springer-Verlag, Berlin, 1984.

31. Salakhov, M. S.; Ismailov, S. A. Russ. Chem. Rev. (Engl. Transl.) 1986, 55, 1145-1163.

32. Craig, D. Chem. Soc. Rev. 1987, 16, 187-238.

33. Roush, W. R. In Comprehensive Organic Synthesis: Trost, B. M.; Fleming, I., Eds., Pergamon, Oxford, 1991, Vol. 5, pp. 513-550.

34. Fallis, A. G. Pure \& Appl. Chem. 1997, 69, 495-500.

35. Fallis, A. G. Can. J. Chem. 1999, 77, 159-177.

36. Fallis, A. G. Acc. Chem. Res. 1999, 32, 464-474.

37. Abad. A.; Agulló, C.; Cuñat, A. C.; Navarro, I.; de Arellano, M. C. R. Synlett 2001, 349-352.

38. a) Padwa, A.; Reger, T. S. Can. J. Chem. 2000, 78, 749-756; see also: b) Padwa, A.; Brodney, M. A.; Dimitroff, M.; Liu, B.; Wu, T. J. Org. Chem. 2001, 66, 3119-3128.

39. Chackalamannil, S.; Davies, R.; McPhail, A. T. Org. Lett. 2001, 3, 1427-1429.

40. Brocksom, T. J.; Constantino, M. G. J. Org. Chem. 1982, 47, 3450-3453.

41. Brocksom, T. J.; Constantino, M. G. An. Acad. Bras.. Ciências. 1982, 54, 655-661.

42. Nakamura, J. unpublished results from our laboratory.

43. Jenkins, P. R. J. Braz. Chem. Soc. 1996, 7, 341-351.

44. Phillips, A. J.; Morris, J. C.; Abell, A. D. Tetrahedron Lett. 2000, 41, 2723-2727.

45. Alunni, S.; Minuti, L.; Pasciuti, P.; Taticchi, A.; Guo, M. Wenkert, E. J. Org. Chem. 1991, 56, 5353-5356.

46. Boeckman, Jr., R. K.; Barta, T. E.; Nelson, S. G. Tetrahedron Lett. 1991, 32, 4091-4094.

47. Diedrich, M. K.; Klarner, F-G.; Beno, B. R.; Houk, K. N.; Senderowitz, H.; Clark Still, W. J. Am. Chem. Soc. 1997, 119, 10255-10259. 
48. Lilly, M. J.; Paddon-Row, M. N.; Sherburn, M. S.; Turner, C. I. Chem. Commun. 2000, 2213-2214.

49. Paddon-Row, M. N.; Sherburn, M. S. Chem. Commun. 2000, 2215-2216.

50. Yakelis, N. A.; Roush, W. R. Org. Lett. 2001, 3, $957-$ 960.

51. Kim, P.; Nantz, M. H.; Kurth, M. J.; Olmstead, M. M. Org. Lett. 2000, 2, 1831-1834.

52. Jung, M. E.; Huang, A.; Johnson, T. W. Org. Lett. 2000 , 2, 1835-1837.

53. Sammes, P. G.; Weller, D. J. Synthesis 1995, $1205-$ 1222.

54. Schelhaas, M.; Waldmann, H. Angew. Chem. Intl. Ed. Engl. 1996, 35, 2057-2083.

55. Bols, M.; Skrydstrup, T. Chem. Rev. 1995, 95, 12531277.

56. Fensterbank, L.; Malacria, M.; Sieburth, S. M. Synthesis 1997, 813-854.

57. Gauthier, D. R.; Zandi, K. S.; Shea, K. J. Tetrahedron 1998, 54, 2289-2338.

58. Delpech, B.; Calvo, D.; Lett, R. Tetrahedron Lett. 1996, 37, 1015-1018.

59. Lilly, M. J.; Sherburn, M. S. Chem. Commun. 1997, 967-968.

60. Handa, S.; Jones, K.; Newton, C. G. J. Chem. Soc., Perkin Trans 1 1995, 1623-1633.

61. Sparks, S. M.; Shea, K. J. Tetrahedron Lett. 2000, 41, 6721-6724.

62. Pérez, D.; Burés, G.; Guitián, E.; Castedo, L. J. Org. Chem. 1996, 61, 1650-1654.

63. a) Tsai, Y-F.; Peddinti, R. K.; Liao, C-C. Chem. Commun. 2000, 475-476; for a similar approach, see: b) Carlini, R.; Higgs, K.; Older, C.; Randhawa, S.; Rodrigo, R. J. Org. Chem. 1997, 62, 2330-2331.

64. Clasby, M. C.; Craig, D.; Jaxa-Chamiec, A. A.; Lai, J. Y. Q.; Marsh, A.; Slawin, A. M. Z.; White, A. J. P.; Williams, D. J. Tetrahedron 1996, 52, 4769-4802.

65. Craig, D.; Geach, N. J.; Pearson, C. J.; Slawin, A. M. Z.; White, A. J. P.; Williams, D. J. Tetrahedron 1995, 51, 6071-6098.

66. Metz, P.; Fleischer, M.; Frohlich, R. Tetrahedron 1995, 51, 711-732.

67. Eto, M.; Uemura, T.; Shimizu, N.; Harano, K. Tetrahedron 1996, 52, 13909-13918.

68. Goldberg, D. R.; Hansen, J. A.; Giguere, R. J. Tetrahedron Lett. 1993, 34, 8003-8006.

69. Toyota, M.; Seishi, T.; Fukumoto, K. Tetrahedron Lett. 1993, 34, 5947-5950.

70. Gwaltney II, S. L.; Sakata, S. T.; Shea, K. J. J. Org. Chem. 1996, 61, 7438-7451.
71. Chou, T.; Chen, H-C.; Yang, W-C.; Li, W-S.; Chao, I.; Lee, S-J. J. Org. Chem. 2000, 65, 5760-5767.

72. Merifield, E.; Thomas, E. J. J. Chem. Soc., Perkin Trans. 1 1999, 3269-3283: Thomas, E. J.; Watts, J. P. J. Chem. Soc., Perkin Trans. 1 1999, 3285-3290.

73. a) Deagostino, A.; Maddaluno, J.; Mella, M.; Prandi, C.; Venturello, J. Chem. Soc., Perkin Trans. 1 1998, 881-888; b) Deagostino, A.; Prandi, C.; Venturello, P. Synthesis 1998, 1149-1152.

74. Sakan, K.; Smith, D. A.; Babirad, S. A.; Fronczek, F. R.; Houk, K. N. J. Org. Chem. 1991, 56, 2311-2317.

75. Park, T. K.; Kim, I. J.; Danishefsky, S. J.; de Gala, S. Tetrahedron Lett. 1995, 36, 1019-1022.

76. Craig, D.; Ford, M. J.; Gordon, R. S.; Stones, J. A.; White, A. J. P.; Williams, D. J. Tetrahedron 1999, 55, 15045-15066.

77. Miyaoka, H.; Kajiwara, Y.; Yamada, Y. Tetrahedron Lett. 2000, 41, 911-914.

78. Back, T. G.; Payne, J. E. Org. Lett. 1999, 1, 663-665.

79. Tashiro, T.; Bando, M.; Mori, K. Synthesis 2000, 18521862.

80. Page, P. C. B.; Jennens, D. C.; McFarland, H. Tetrahedron Lett. 1997, 38, 6913-6916.

81. Nemoto, H.; Satoh, A.; Fukumoto, K. Tetrahedron 1995, 51, 10159-10174.

82. Heiner, T.; Kozhushkov, S. I.; Noltemeyer, M.; Haumann, T.; Boese, R.; de Meijere, A. Tetrahedron 1996, 523, 12185-12196.

83. Dzierba, C. D.; Zandi, K. S.; Mollers, T.; Shea, K. J. J. Am. Chem. Soc. 1996, 118, 4711-4712.

84. Stork, G.; Chan, T. Y. J. Am. Chem. Soc. 1995, 117, 6595-6596.

85. Batey, R. A.; Thadani, A. N.; Lough, A. J. J. Am. Chem. Soc. 1999, 121, 450-451.

86. Bertozzi, F.; Olsson, R.; Frejd, T. Org. Lett. 2000, 2, 1283-1286.

87. Ward. D. E.; Abaee, M. S. Org. Lett. 2000, 2, $3937-$ 3940.

88. Evans, D. A.; Black, W. C. J. Am. Chem. Soc. 1993, 115, 4497-4513.

89. Evans, D. A.; Johnson, J. S. J. Org. Chem. 1997, 62, 786-787.

90. Schnaubelt, J.; Frey, B.; Reissig, H-U. Helv. Chim. Acta 1999, 82, 666-676.

91. Suzuki, Y.; Nishimaki, R.; Ishikawa, M.; Murata, T.; Takao, K.; Tadano, K. J. Org. Chem. 2000, 65, 85958607.

92. Jauch, J. Synlett. 2001, 87-89.

93. Shing, T. K. M.; Jiang, Q. J. Org. Chem. 2000, 65, 7059-7069. 
94. Hudlicky, T.; Gonzalez, D.; Gibson, D. T. Aldrichimica Acta 1999, 32, 35-62.

95. Dorr, H.; Rawal, V. H. J. Am. Chem. Soc. 1999, 121, 10229-10230.

96. Grieco, P. A.; Kaufman, M. D. J. Org. Chem. 1999, 64, 6041-6048.

97. Muller, G.; Jas, G. Tetrahedron Lett. 1992, 33, 44174420.

98. Journet, M.; Malacria, M. J. Org. Chem. 1994, 59, 6885-6886.

99. Jones, P.; Li, W-S.; Pattenden, G.; Thomson, N. M. Tetrahedron Lett. 1997, 52, 9069-9072.

100. Deslongchamps, P. Aldrichimica Acta 1991, 24, 4356.

101. Deslongchamps, P. Pure \& Appl. Chem. 1992, 64, 1831-1847.

102. Dory, Y. L.; Soucy, P.; Drouin, M.; Deslongchamps, P. J. Am. Chem. Soc. 1995, 117, 518-529.

103. Couturier, M.; Dory, Y. L.; Rouillard, F.; Deslongchamps, P. Tetrahedron 1998, 54, 1529-1562.

104. Couturier, M.; Dory, Y. L.; Fortin, D.; Rouillard, A.; Deslongchamps, P. Tetrahedron 1998, 54, 1008910110.

105. Toró, A.; Wang, Y.; Deslongchamps, P. Tetrahedron Lett. 1999, 40, 2765-2768.

106. Toró, A.; Wang, Y.; Drouin, M.; Deslongchamps, P. Tetahedron Lett. 1999, 40, 2769-2772.

107. Toró, A.; L'Hereux, A.; Deslongchamps, P. Org. Lett. 2000, 2, 2737-2740.

108. Bélanger, G.; Deslongchamps, P. J. Org Chem. 2000, 65, 7070-7074.

109. Shing, T. K. M.; Yang, J. J. Org. Chem. 1995, 60, $5785-$ 5789.

110. Frank, S. A.; Works, A. B.; Roush, W. R. Can J. Chem. 2000, 78, 757-771.

111. Tius, M.A. Chem. Rev. 1988, 88, 719-732.

112. Stach, H.; Hesse, M. Tetrahedron 1988, 44, 1573-1590.

113. Rousseau, G. Tetrahedron 1995, 51, 2777-2849.
114. Armstrong, S. K. J. Chem. Soc., Perkin Trans. 1 1998, 371-388.

115. Grubbs, R. H.; Chang, S. Tetrahedron 1998, 54, 44134450.

116. Gibson, S. E.; Middleton, R. J. Contemp. Org. Synth. 1996, 3, 447-471.

117. Handa, S.; Pattenden, G. Contemp. Org. Synth. 1997, 4, 196-215.

118. Duncton, M. A. J.; Pattenden, G. J. Chem. Soc., Perkin Trans. 1 1999, 1235-1246.

119. Marsault, E.; Deslongchamps, P. Org. Lett. 2000, 2, 3317-3320.

120. Collins, I. J. Chem. Soc., Perkin Trans. 1 1999, $1377-$ 1395.

121. Marshall, J. A.; Liao, J. J. Org. Chem. 1998, 63, 59625970.

122. Liu, M. T. H.; Schmidt, C. Tetrahedron 1971, 27, 5289-5297.

123. Spino, C.; Pesant, M.; Dory, Y. Angew. Chem. Int. Ed. Engl. 1998, 37, 3262-3265.

124. Bear, B. R.; Sparks, S. M.; Shea, K. J. Angew. Chem. Int. Ed. Engl. 2001, 40, 820-849.

125. Marsault, E.; Toró, A.; Nowak, P.; Deslongchamps, P. Tetrahedron 2001, 57, 4243-4260.

126. Miyaoka, H.; Kajiwara, Y.; Hara, Y.; Yamada, Y. J. Org. Chem. 2001, 66, 1429-1435.

127. Turner, C. I.; Williamson, R. M.; Paddon-Row, M. N.; Sherburn, M. S. J. Org. Chem. 2001, 66, 39633969.

128. Back, T. G.; Nava-Salgado, V. O.; Payne, J. E. J. Org. Chem. 2001, 66, 4361-4368.

129. Report in $C \& E$ News, January 8, 2001, pp. 27-29.

130. García, J. I.; Mayoral, J. A.; Salvatella, L. Acc. Chem. Res. 2000, 33, 658-664.

Received: June 11, 2001

Published on the web: August 15, 2001

FAPESP helped in meeting the publication costs of this article. 